\section{La incentivación del empleo de las personas con discapacidad en el medio ordinario de trabajo ${ }^{1}$}

\section{Promotion of the employment of people with disabilities in the open labour market}

\section{Resumen}

El artículo constituye un examen crítico de los principales incentivos a la contratación de personas con discapacidad en el mercado ordinario de trabajo, es decir, las bonificaciones en materia de Seguridad Social y las subvenciones por contratación, a la luz del nuevo Texto Refundido de Ley General de derechos de las personas con discapacidad y de su inclusión social (Real Decreto Legislativo I/20I3) y de la Estrategia de Acción para el Empleo de las Personas con Discapacidad 2008-20I 2. Son objeto de análisis la normativa y la jurisprudencia dictada al efecto. En el artículo se analiza el alcance cuantitativo de las bonificaciones, los contratos beneficiados y el régimen jurídico de las exclusiones legales que pueden impedir su disfrute. En materia de subvenciones económicas se estudian la cuantía de la subvención por contratación, el concepto de persona con discapacidad beneficiaria o la compatibilidad entre las subvenciones estatales y autonómicas. En fin, también se aborda la subvención por adaptación de puesto de trabajo.

\begin{abstract}
This paper is aimed at a critical analysis of the main tools existing in Spain to foster the employment of people with disabilities in the open labour market considering the new Consolidated Text of the General Act on the Rights of People with Disabilities and its social inclusion (Royal Legislative Decree I/20I3) and the Global Strategy on Employment of People with Disabilities 2008-20I2. The main incentives are reductions in Social Security contributions and financial bonuses. The paper's methodology is based in the study of both the law and the case law. Firstly, with regard to the reductions in Social Security contributions, the paper evaluates its reach, the different types of employment contracts concerned and the circumstances which could hamper employers' access to bonuses. Secondly, the article evaluates some key issues regarding employment grants like their amount, the specific concept of disabled person to be hired or the possibility to pile up national and autonomous (regional) grants. Finally, the article evaluates the existing limited grant to carry out workplace adjustments.
\end{abstract}

\section{Keywords}

Open employment, reductions in Social Security contributions, financial bonuses, Global Strategy 2008-20I2.

I. El presente artículo se publica en el marco del proyecto de investigación I+D DER 20IO-I 5855 (subprograma JURI), Análisis jurídico-laboral de la Estrategia Global de Empleo de las Personas con Discapacidad 2008-20I2, financiado por el Ministerio de Economía y Competitividad y dirigido por el profesor Ricardo Esteban Legarreta, coautor de este artículo.

\section{Palabras clave}

la Seguridad Social, subvenciones,

Estrategia Global 2008-20I2.

\section{Ricardo Esteban Legarreta \\ <ricardo.esteban@uab.cat>}

Profesor titular de Derecho del Trabajo y de la Seguridad Social. Universidad

Autónoma de Barcelona

\section{David Gutiérrez Colominas}

<david.gutierrezco@e-campus.uab. cat>

Abogado en ejercicio. Doctorando en Derecho del Trabajo y de la Seguridad Social. Universidad Autónoma de Barcelona

Para citar:

Esteban Legarreta, R. y Gutiérrez

Colominas, D. (2OI4): "La incentivación del empleo de las personas con discapacidad en el medio ordinario de trabajo". Revista Española de Discapacidad, 2 (I): 7-32.

<http://dx.doi.org/IO.5569/23405 IO4.02.OI.OI>

Fecha de recepción: I4-O2-2OI4 Fecha de aceptación: 05-05-20I4

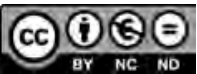




\section{Nota del Editor}

A efectos de edición, y por garantizar al lector la adecuada identificación de las referencias legislativas del artículo, se ha conservado el término "minusválido" en los textos jurídicos originales que incluían dicho término y que a fecha de hoy no se han modificado, tal y como correspondería por la Disposición adicional octava de la Ley 39/2006, de I4 de diciembre, de Promoción de la Autonomía Personal y Atención a las personas en situación de dependencia. Los autores consideran que los términos minusválido y persona con minusvalía deben entenderse sustituidos por discapacidad y persona con discapacidad, de acuerdo con dicha disposición.

\section{Planteamiento}

Los incentivos al empleo de las personas con discapacidad constituyen un elemento de relevancia indiscutible que suscita el interés del asociacionismo y de entornos académicos y empresariales. La pretensión de este artículo es abundar en la reflexión de dos incentivos de notable relevancia en la contratación de personas con discapacidad: las bonificaciones a la cuota patronal a la Seguridad Social por la contratación de trabajadores con discapacidad y las subvenciones económicas directas, tanto la estatal regulada en el Real Decreto I45I/I983, de i I de mayo, por el que se regula el empleo selectivo o las medidas de fomento del empleo de los trabajadores minusválidos ${ }^{2}$, como las autonómicas, dirigidas por lo general a complementar a aquella. Ciertamente, dentro de una noción amplia y flexible de incentivo cabe incluir igualmente otros mecanismos como la reserva de empleo o el empleo con apoyo, pero dado su carácter central, nos limitaremos a un análisis de las bonificaciones y de la subvención.

2. BOE, núm. I33, de 4 de junio de 1983 .
En este sentido, el presente artículo se va a centrar en un análisis de los incentivos desde la lógica y la perspectiva de la Estrategia Global de Empleo de las Personas con Discapacidad 20082012 (en adelante Estrategia Global)3 también en consideración las grandes líneas del nuevo Texto Refundido de la Ley General de Derechos de las Personas con Discapacidad y de su Inclusión Social, aprobada mediante el Real Decreto-Legislativo I/2013, de 29 de noviembre 4 (en adelante LGDPD). No obstante, cabe resaltar dos matices importantes respecto al alcance y la significación de la LGDPD en esta materia. El primero, que la LGDPD no aporta en general grandes novedades respecto a la legislación básica anterior, ya que se trata de un texto en el que se recoge el contenido refundido y armonizado de, entre otras, dos normas clave: la Ley I3/I982, de 7 de abril, de integración social de los minusválidos ${ }^{5}$ (en adelante LISMI), y la Ley 5i/2003 de 2 de diciembre $^{6}$, de igualdad de oportunidades, no discriminación, y accesibilidad universal de las personas con discapacidad (en adelante LIONDAU). En este sentido, debe tenerse en cuenta que un texto refundido no debe comportar ningún cambio significativo respecto a los textos que son objeto de refundición (artículo 82.5 de la Constitución Española), aunque como veremos en aspectos concretos esto no ha sido así en el proceso de elaboración de la LGDPD. Además, la LGDPD no regula con detalle los incentivos a la contratación de las personas con discapacidad, sino que es un texto marco que establece algunos grandes principios posteriormente desarrollados por otras leyes y disposiciones reglamentarias, como sucede con las bonificaciones y subvenciones a la contratación en el mercado ordinario de trabajo.

Entre los principios básicos en materia de empleo reflejados en la LGDPD sí que hay algunas novedades. Así, destacan dos principios novedosos como son el principio dirigido a aumentar las tasas de actividad y de

3. Documento aprobado por el Consejo de Ministros el 26 de septiembre de 2008 .

4. BOE, núm. 289, de 3 de diciembre de 2013.

5. BOE, núm. Iо3, de 30 de abril de 1982 .

6. BOE, núm. 289 , de 3 de diciembre de 2003 . 
empleo e inserción laboral de las personas con discapacidad y el principio dirigido a la mejora de la calidad en el empleo y la dignificación de condiciones de trabajo, reflejados ambos en el artículo 37.I de la LGDPD. El primero de los principios señalados cuenta con el refuerzo del artículo 39.I LGDPD (antiguo artículo 38.4 LISMI) al prever que el empleo de las personas con discapacidad se fomentará mediante ayudas públicas, pudiendo consistir estas, entre otras, en subvenciones y bonificaciones en las cuotas a la Seguridad Social. Como veremos, el segundo de los principios, dirigido a la mejora de la calidad en el empleo, es coincidente con la Estrategia Global de Empleo. Asimismo, el artículo 43.I de la LGDPD conserva el principio de transición del empleo en Centro Especiales al medio ordinario de trabajo, previsto en la LISMI de I982.

En materia de principios, la LGDPD destaca por la sorprendente supresión del principio de preferencia por el empleo de las personas con discapacidad en el medio ordinario de trabajo, que provenía del artículo 37.I de la LISMI y que ha sido suprimido de modo absolutamente injustificado, desde una triple perspectiva. Así, a) se ha suprimido un principio básico utilizando la aprobación del Real Decreto-Legislativo I/20I3 de refundición a cargo del Gobierno, que solo permite armonizar, aclarar o regularizar textos legales, no cambiar el contenido de la Ley suprimiendo principios que no generaban ninguna duda; b) se ha suprimido este principio, sin hacer referencia alguna a ello, en la exposición de motivos del Real Decreto-Legislativo I/20I3, lo que todavía es más llamativo y, en fin, c) se ha suprimido el principio en total contradicción con el artículo 27 del Instrumento de ratificación de la Convención sobre los Derechos de las Personas con Discapacidad, hecho en Nueva York el I 3 de diciembre de $2006^{7}$, texto internacional vinculante para España tras su ratificación (artículo 96 de la Constitución Española) y que promueve la inserción laboral en un mercado y entorno laboral abierto, inclusivo y accesible. Todo apunta a que la supresión del principio de preferencia por el empleo en el medio ordinario de trabajo procede de la ya señalada (Esteban,

7. BOE, núm. 96, de 2 I de abril de 2008.
2013: 70) presión de grupos empresariales titulares de Centros Especiales de Empleo con una fuerte capacidad de incidencia en el CERMI, que es la entidad que a la postre ha mantenido una posición prominente en el diálogo civil con el Gobierno, que ha desembocado en la aprobación de la LGDPD. Desgraciadamente, la súbita y sorprendente supresión del principio de preferencia por el empleo en el medio ordinario de trabajo puede bloquear en un futuro algunas de las más interesantes mejoras propuestas en la Estrategia Global.

Por su parte, la Estrategia Global de Acción para el Empleo de las Personas con Discapacidad 2008-20I 2 ha sido un documento político de gran relevancia, que pretendió vehicular una ambiciosa, detallada y profunda transformación en el régimen jurídico del empleo de las personas con discapacidad, razón por la que su protagonismo es clave en este artículo. Originada en la disposición adicional duodécima de la Ley 43/2006, de 29 de diciembre, para la mejora del crecimiento y del empleo ${ }^{8}$ (en adelante Ley 43/2006), la Estrategia Global, pactada entre el Gobierno del Estado, el Comité Español de Representantes de Personas con Discapacidad (en adelante CERMI) y las centrales sindicales y organizaciones patronales más representativas, en un difícil equilibrio entre diálogo civil y diálogo social (Ysas, 20I3: I98) ha transitado con escasa huella durante su vigencia temporal, ya que apenas ha activado las reformas previstas (Esteban, 2013: 70). Sin embargo, entendemos que los planteamientos de la Estrategia Global permanecen vigentes, y el marco regulador podría adaptarse a ellos sin grandes estridencias, más allá de que en algunos extremos exista ya una razonable proximidad entre norma y Estrategia Global. Ello nos ha llevado a combinar el análisis de los incentivos a través de las grandes líneas de la nueva LGDPD y las orientaciones de la Estrategia Global, ya que entendemos que este último documento constituye una base fundamental para acometer las reformas que procedan en materia de incentivos. Asimismo, se advierte que el análisis de la incentivación se va a centrar fundamentalmente en el fomento

8. BOE, núm. 3I2, de 30 de diciembre de 2006. 
del empleo en el medio ordinario de trabajo, dado que los incentivos actualmente vigentes en materia de empleo protegido han sido objeto de exhaustivos comentarios en otra obra publicada por este equipo de investigación (Esteban y Pérez, 2009: 30I), comentarios que por lo demás seguían la lógica de la documentación que precedió a la Estrategia Global. Como es natural, no abordar un análisis de los incentivos para el empleo en Centros Especiales de Empleo (en adelante CEE) no obstará la inevitable referencia comparativa entre los incentivos previstos para empleo ordinario y para el empleo en Centros. A continuación, procederemos a exponer las grandes líneas de la Estrategia Global a este respecto.

Con carácter general, la Estrategia Global propuso en su objetivo operativo número $4^{9}$, dedicado a "Promover una mayor contratación de personas con discapacidad en el mercado de trabajo ordinario", la línea de actuación 4.9, dedicada a "Incentivos a la contratación", que parte de una ambiciosa declaración de intenciones según la cual debían estudiarse los costes, tanto fijos como variables, soportados por las empresas contratantes de trabajadores con discapacidad, teniendo en cuenta el tipo de discapacidad, su severidad, sexo, edad y tamaño de la empresa. Lamentablemente, el estudio no se ha realizado ni tampoco la revisión global del régimen jurídico de los incentivos que debía llevarse a cabo en base a una serie de principios recogidos en la línea de actuación 4.9, que se señalan a continuación y que entendemos como plenamente vigentes y de notable utilidad práctica.

En cuanto a los principios reseñados y siguiendo un orden de menor a mayor abstracción cabe destacar, de un lado, las propuestas de a) "asegurar que los incentivos a la contratación no supongan una barrera al desarrollo profesional de los trabajadores con discapacidad"; b) la

9. Los objetivos operativos constituyen el núcleo básico de la Estrategia Global, centrándose en aspectos clave, como son, entre otros, los de potenciar la formación y la educación de la personas con discapacidad; diseñar nuevas políticas activas de empleo; renovar el empleo protegido o, en fin, mejorar la calidad en el empleo y las condiciones de trabajo de las personas con discapacidad. "posibilidad de modular los incentivos según el tipo y grado de discapacidad, el sexo y la edad", así como c) "procurar la suficiencia de los recursos económicos destinados a la contratación de personas con discapacidad en el empleo ordinario" una suerte de mantra, este último principio, que también se subraya en materia de empleo protegido y que recuerda las dificultades que se vislumbraban ya en 2008 en este terreno. Así, en diversas comunidades autónomas (en adelante CCAA) no hay suficiencia presupuestaria para cubrir la cuantía de los incentivos, lo que ha generado su reducción a prorrata en el caso de las subvenciones salariales en Centros, en aplicación de la Ley 38/2003, de I 7 de noviembre, General de Subvenciones ${ }^{10}$ (Esteban, 2013:59-60), y en el caso de las subvenciones a la contratación en la empresa ordinaria, su suspensión sine die ${ }^{\mathrm{II}}$.

A partir de aquí destaca un cuarto principio que debería llevar a d) sobreincentivar la contratación de personas con discapacidad cuando la empresa no esté obligada al cumplimiento de la reserva de empleo, o bien cuando contrate por encima de su obligación de reserva $^{12}$. Es de lamentar el tímido planteamiento de la medida, ya que la Estrategia Global simplemente proponía "estudiar la viabilidad" de un sistema especial de reducciones o bonificaciones a la Seguridad Social, una suerte de "pre propuesta" que se planteaba con enorme prudencia teniendo en cuenta la pretensión de mantener el statu quo; una idea que ha acompañado todo el proceso de ejecución de la Estrategia Global de 2008 (Esteban, 2013: 70). A nuestro juicio, la propuesta era más que plausible y encajaba perfectamente en un planteamiento

Io. $B O E$, núm. 276 , de I 8 de noviembre de 2003 . I I. Ese es el caso de Cataluña. Según información del Departamento de Empresa y Empleo de la Generalitat de Cataluña desde hace dos años no se convocan las subvenciones económicas a la contratación en la empresa ordinaria, comentadas más adelante.

I2. Concretamente, la línea de actuación 4.9 incluía la propuesta de estudiar la "Viabilidad de un sistema de reducción o bonificación de las cotizaciones sociales para las empresas que contraten personas con discapacidad por encima de su obligación de reserva o que contraten sin estar obligadas por tener menos de 50 trabajadores". 
racionalizador de los incentivos que finalmente, no se ha hecho efectivo.

En fin, un quinto y último principio sugería que e) la reforma de los incentivos se llevase a cabo siguiendo un criterio de calidad en el empleo -línea fuerza básica de la Estrategia Global muy presente en el objetivo operativo número 6-, sin mayores explicaciones ni detalles, de modo que tal y como se ha planteado, la propuesta constituye poco más que un mero brindis al sol. En este sentido, la no identificación de estándares de calidad en el empleo y la verificación de su cumplimiento plantean dificultades, aunque algún dato podemos extraer de este principio. Como se verá, la calidad en el empleo podría ser un factor a considerar en la incentivación del empleo temporal, y a la hora de evitar la penalización de retribuciones que estén por encima de la básica; ya sea la retribución de convenio colectivo, ya se trate de la retribución mínima legal; a saber, el salario mínimo interprofesional.

Tras este breve recordatorio del planteamiento de la Estrategia Global y de las aportaciones de la LGDPD se abordará el comentario crítico de las principales medidas de incentivación existentes: bonificaciones en las cuotas patronales a la Seguridad Social (I) y subvenciones por contratación de personas con discapacidad (2), un conjunto de ayudas que "están diseñadas para hacer frente tanto a los costes fijos (al contratar) como a los costes variables (durante la relación laboral) más altos asociados a tener un trabajador con discapacidad" (Rodríguez et al, 2009: 7I).

\section{Las bonificaciones de cuotas empresariales a la Seguridad Social en el marco del empleo de las personas con discapacidad}

Las bonificaciones dirigidas a la incentivación del empleo de las personas con discapacidad se encuentran reguladas actualmente en la
Ley $43 / 2006$, texto en el que se recogen los incentivos tanto para el medio ordinario de trabajo como para la contratación en entornos protegidos. Se trata de una regulación fruto del accidentado planteamiento de convergencia regulatoria (Esteban y Pérez, 2009:3 I6), operado mediante el Real Decreto-Ley 5/2006, de 9 de junio, para la mejora del crecimiento y del empleo ${ }^{13}$, a la sazón antecedente de la Ley 43/2006, que optó por regular en un único texto los sistemas de bonificación a la Seguridad Social precedentes, regulados en su día en el Real Decreto I45I/I 983 para el empleo ordinario y en la Orden de 16 de octubre de I998, por la que se establecen las bases reguladoras para la concesión de las ayudas y subvenciones públicas destinadas al fomento de la integración laboral de los minusválidos en centros especiales de empleo y trabajo autónomo ${ }^{\mathrm{I4}}$. Más allá de los detalles que acompañan a esta regulación y que abordaremos a continuación, se ha de destacar que la supresión generalizada de bonificaciones a la Seguridad Social operada mediante el Real Decreto-Ley 20/20I2, de I 3 de julio, de medidas para garantizar la estabilidad presupuestaria y de fomento de la competitividad ${ }^{15}$, realza el interés del mantenimiento de estos incentivos, si bien debe tenerse en cuenta que su supresión habría sido totalmente inasumible políticamente, sobre todo teniendo en cuenta la generosidad con la que se formulan para el empleo protegido. Al respecto, cabe recordar que los centros disfrutan de bonificaciones totales en la cuota patronal de Seguridad Social por la contratación de todo trabajador con discapacidad. De cualquier modo, no deja de ser llamativo, y también positivo, que las bonificaciones a la contratación de personas con discapacidad hayan quedado inalteradas, tanto en el terreno de la empresa ordinaria como en el del empleo protegido; máxime teniendo en cuenta que, por lo general, su cuantía es mucho más elevada que la prevista para la contratación de otros colectivos vulnerables (Alemán y Grau, 20I I: 37; Rodríguez et al, 2009: 70), como es el caso de las personas en situación de exclusión

\footnotetext{
I3. BOE, núm. I4 I, de I4 de junio de 2006.

I4. $B O E$, núm. 279 , de 2 I de noviembre de 1998 .

I 5. BOE, núm. I68, de I4 de julio de 20 I 2.
} 
social, que generan una bonificación básica por contrato indefinido de 50 euros al mes durante cuatro años, mientras que las bonificaciones más bajas por contratación indefinida de personas con discapacidad ascienden a 375 euros al mes, sin tope temporal.

\subsection{El alcance de las bonificaciones por la contratación de las personas con discapacidad}

\subsubsection{Trabajador con discapacidad, forma de la bonificación, contratación afectada y circunstancias consideradas.}

\section{A. Trabajadores con discapacidad beneficiarios}

El artículo 2.2 de la Ley 43/2006 aborda la regulación de los aspectos básicos de la bonificación por contratación en entornos ordinarios y protegidos. El concepto básico de persona con discapacidad es formulado de un modo abierto y flexible, que ha acabado consolidándose mediante la LGDPD (artículo 4), de modo que se incluyen con carácter general y para la bonificación mínima prevista, además de las personas con discapacidad con un grado no inferior al $33 \%$, los titulares de pensiones de Seguridad Social por incapacidad permanente en grado de total o superior y, también, los titulares de pensiones de clases pasivas que tengan reconocida una pensión de jubilación o de retiro por incapacidad permanente para el servicio o inutilidad (artículo 2.2 5) Ley 43/2006).

\section{B. Forma de la bonificación}

Más allá de las bondades y de los defectos de esta asimilación de los pensionistas de incapacidad permanente a persona con discapacidad ${ }^{16}$, otro rasgo de importancia en las bonificaciones a la contratación de personas con discapacidad se encuentra en la forma de las mismas, basada en

I6. Los defectos de la asimilación están en que se tiende a tratar del mismo modo realidades muy diferentes, que necesitarían por lo tanto, de una atención diferenciada. No obstante, en este caso la Ley 43/2006 establece bonificaciones ponderadas en base a la gravedad de la discapacidad de los trabajadores afectados. una cuantía máxima de bonificación por mes. A título de ejemplo, la contratación indefinida de trabajadores con una discapacidad no grave se incentiva con una bonificación máxima de 375 euros al mes. Al respecto y como es de sobra conocido, con anterioridad a 2006 las bonificaciones se formulaban siempre y en todo caso como un porcentaje sobre el total de la cuota empresarial. De este modo, la bonificación básica del Real Decreto I45I/I983 era de un 70\% del conjunto de la cuota empresarial de Seguridad Social. Con la reforma de la Ley 43/2006, el criterio se modifica para pasar a bonificaciones fundamentadas en cuantías máximas, lo que permite visualizar mejor el beneficio, pero a su vez puede generar importantes defectos. El primero de ellos es el de la congelación de las cuantías bonificadas cuando no se aborde una actualización sistemática de las mismas (Alemán y Grau, 20I I: 36). Todo ello sin olvidar consecuencias apreciables en materia de calidad en el empleo a las que nos referiremos más adelante.

\section{Contratación afectada y circunstancias consideradas}

Por lo demás, la bonificación alcanza a la contratación temporal y a la indefinida, a tiempo completo y a tiempo parcial, de modo que se prioriza el aumento del empleo sobre la reducción de la temporalidad (Alemán y Grau, 2OI I: 38 ), lo que sería coherente con el texto de la LGDPD (artículo 37.I) en la que se preconiza como principio, precisamente, el aumento de la tasa de empleo e inserción de las personas con discapacidad. En particular, el régimen de incentivación de contratos a tiempo parcial es satisfactorio ya que afecta con carácter general a la contratación indefinida. Respecto a la bonificación de contratos temporales a tiempo parcial, ésta se limita a la contratación temporal para el fomento del empleo de las personas con discapacidad (disposición adicional primera de la Ley 43/2006), que se mueve entre una duración mínima de un año y una duración máxima de tres años. Además, cabe subrayar que la bonificación a la contratación a tiempo parcial cuenta con un interesante recargo compensatorio previsto 
en el artículo 2.7 de la Ley 43/2006, de acuerdo con el cual la bonificación será el resultado de aplicar el porcentaje de la jornada realizada a la bonificación prevista para la contratación a tiempo completo. Ahora bien, a dicho porcentaje se le aplicarán 30 puntos porcentuales adicionales sin que, lógicamente, el resultado final "pueda superar el $100 \%$ de la cuantía prevista” ${ }^{{ }^{7}}$. A este respecto, el planteamiento de la bonificación por la contratación a tiempo parcial refleja una acertada consideración de esta contratación y el deseo de que la bonificación transmita al empresario la idea de un beneficio tangible y de un cierto alcance, por lo que para este caso, como veremos, la utilización de una cifra económica de bonificación por cada contrato, ha obligado al legislador a elevarla para evitar una sensación de cicatería. De todos modos, entendemos que la incentivación de los contratos a tiempo parcial debiera ser más abierta en el caso de la contratación temporal, cuando esta sea la vía de inserción mediante empleo con apoyo, de personas con discapacidad afectada por especiales dificultades. De ahí que queramos insistir, aunque sea con cierta prudencia, en la necesidad de que los otros contratos temporales a tiempo parcial "apoyados", es decir, contratos de obra y eventuales deberían contar con esta suerte de bonificaciones, aunque sea sin el beneficio del porcentaje adicional del $30 \%{ }^{18}$.

Respecto a las cuantías de bonificación, la Ley establece diferenciadas en base a circunstancias ya consideradas por la Estrategia Global como son la edad, el sexo o la discapacidad del trabajador, de modo que en esta materia el planteamiento general de la Estrategia ya había sido tenido en cuenta por la Ley 43/2006 con anterioridad a la

I7. Ello significará a título de ejemplo, que en caso de contratación al $50 \%$ de un trabajador al que corresponda una bonificación a tiempo completo equivalente a 375 euros, le correspondería en principio una bonificación del $50 \%$; es decir, de I 87 ' 5 euros. Ahora bien, a esa cuantía de bonificación se le añadirá un $30 \%$ más (I I 2'5 euros), lo que va a comportar un beneficio final de 300 euros, cifra muy cercana a la de los 375 euros previstos para una contratación a tiempo completo. I 8. Debe tenerse en cuenta que el buen trato atribuido en general a la contratación a tiempo parcial es muy importante, ya que un número apreciable de personas con discapacidad no pueden desempeñar una jornada a tiempo completo, de modo que para ellas el contrato a tiempo parcial no es una figura precarizante en modo alguno. Ver al respecto, el apartado I.I.3. aprobación de aquel documento. A este respecto, las bonificaciones se diferenciarán en primer lugar en base a la gravedad de la discapacidad, circunstancia que constituye un criterio clave y que se pondera al alza, en su caso, en base a la edad y al sexo, elementos secundarios con un planteamiento razonable y que cumplirían aceptablemente y en su conjunto con las propuestas de la Estrategia Global.

\subsubsection{Bonificación por contratación indefinida}

La bonificación mensual básica por la contratación indefinida a tiempo completo asciende a 375 euros al mes $(4.500$ euros al año), que se calculará por días cuando el mes no se cotice al completo. La bonificación alcanzará toda la vida del contrato y se aplicará también a la transformación de contratos temporales de fomento del empleo y formativos en contratos indefinidos. La bonificación se pondera al alza si se trata de trabajadores afectados de especiales dificultades, ya que en tales casos la bonificación se elevará en 50 euros $(425$ euros mensuales, 5. I00 euros anuales). Se entiende por trabajadores afectados por especiales dificultades: a) personas con parálisis cerebral, personas con enfermedad mental o personas con discapacidad intelectual con un grado de discapacidad reconocido, igual o superior al $33 \%$ y b) personas con discapacidad física o sensorial, con un grado de discapacidad reconocido igual o superior al $65 \%$. En fin, la Ley pondera al alza la bonificación prevista en base a la edad y al sexo del trabajador (artículo 2.2.3 de la Ley 43/2006), de modo que de alcanzarse los 45 años de edad, se tendrá derecho a un incremento de Ioo euros mensuales (I.200 euros al año). Asimismo, cuando se contrate a mujeres la bonificación mensual adicional será de 70'83 euros mensuales (850 euros al año), aunque en caso de coincidir el factor de edad y el de género en la trabajadora a contratar, "los incrementos establecidos en este número serán incompatibles entre sí”.

Desde una perspectiva crítica deben efectuarse una serie de puntualizaciones importantes en espera de futuras reformas. En primer lugar, 
cabe felicitarse porque la bonificación se aplique al conjunto de la cuota empresarial, por lo que las posibilidades de aprovechamiento de la bonificación son más amplias ${ }^{19}$. Dicho eso, entendemos imprescindible una mejora en materia de bonificaciones por la contratación de trabajadores afectados por especiales dificultades, que debería traducirse en una bonificación total, lo que se fundamentaría en diversos argumentos. De un lado, una realidad práctica que sugiere que el actual montante de bonificación máxima general de 425 euros, comportará en muchos casos la exención de obligaciones en materia de Seguridad Social o bien una situación cercana a la bonificación total. Así, según datos extraídos del Instituto Nacional de Estadística para $2010^{20}$ el salario medio de las personas con discapacidad intelectual fue de I2.7 I6'5 euros, lo que técnicamente dejaría a los empleadores de estos trabajadores como exentos de la obligación de cotizar teniendo en cuenta que su base de cotización media sería de I.059 euros mensuales, lo que con mucha frecuencia va a generar una cuota patronal inferior o a los 425 euros $^{21}$. Para el caso de personas con enfermedad mental, las cifras del salario medio de $2010^{22}$, que se cifran en I7.016'9 euros anuales, sugerirían que para la contratación a tiempo completo la

I9. Téngase en cuenta que en las cotizaciones empresariales están las aportaciones a contingencias comunes (entre otras, jubilación, maternidad, incapacidad temporal, permanente y muerte y supervivencia por enfermedad o accidente común) pero también están las cotizaciones por otros conceptos como el accidente de trabajo y la enfermedad profesional o bien las cuotas de recaudación conjunta que comportan la aportación de cotizaciones por desempleo, fondo de garantía salarial y formación profesional.

20. Instituto Nacional de Estadística: "El salario de las personas con discapacidad. Año 20Io, Notas de Prensa INE”, 5 de junio de 2013 , p. 6.

2I. A título de ejemplo y partiendo de un trabajador con contrato indefinido, si tomamos los tipos previstos para $20 \mathrm{I} 4$ por contingencias comunes, desempleo, fondo de garantía salarial y formación profesional resulta un total del 29'9 por Ioo, que aplicado a una base de I.059 euros resultaría una cuota de 3 I 6’64 euros. Ciertamente, faltaría añadir la cuota por contingencias profesionales pero es evidente que por lo general y teniendo en cuenta las actividades desempeñadas por personas con discapacidad, la misma no irá más allá de un 2 o 2's por roo adicional de modo que se confirma lo señalado en el texto principal.

22. Instituto Nacional de Estadística: "El salario de las personas con discapacidad. Año 20Io", Notas de Prensa INE, 5 de junio de 2013 , p. 6. base de cotización promedio, que alcanzaría los I.4 I 8 euros, generaría modestas obligaciones de cotización, que desaparecerían en muchos casos si la persona contratada es un trabajador de edad o una mujer ${ }^{23}$. A partir de estos datos, nos parece mucho más razonable la bonificación completa, tanto en contratos a tiempo completo como en contratos a tiempo parcial, exención que significaría un claro espaldarazo a la actitud empresarial proclive a este tipo de contrataciones, teniendo en cuenta que "el colectivo con discapacidad severa tiene un gran déficit educativo y una tasa de inactividad que duplica la de la población sin discapacidad y es veinte puntos porcentuales superior a la de las personas con discapacidad moderada" (Rodríguez et al., 2009: IOI-IO2). Todo ello simplificaría la gestión de las bonificaciones a la Seguridad Social del colectivo y asimilaría su trato al disfrutado por los CEE. El problema está en que este planteamiento no cuenta ya con el respaldo del principio de preferencia por el empleo en el medio de trabajo, suprimido del texto de la LGDPD. De cualquier modo, es un auténtico despropósito que se mantengan, al menos formalmente, moderadas obligaciones de cotización de estos colectivos al tiempo que se exime de cotización cualquier contratación de trabajadores con discapacidad, con o sin especiales dificultades, realizada por CEE. Eso sí, nos parecería razonable mantener una moderada obligación de cotización para los contratos de obra o servicio determinado y eventuales

23. Obsérvese que el cálculo de la cuota patronal (salvo contingencias profesionales) resultaría una cuota promedio de 423 '98, resultado de aplicar a la base promediada de I.4I 8 euros, el tipo de 29 '9 \% (suma de contingencias comunes, desempleo [contrato indefinido], formación profesional y fondo de garantía salarial). Para el caso de trabajadores con discapacidad física en grado igual o superior al $65 \%$, no consta el salario promedio en los datos del INE, ya que se encuentran dentro del conjunto de los trabajadores con discapacidad física, con un salario promedio de 21.5 59,7 euros. En todo caso, parece evidente que su salario va a estar sensiblemente por debajo de esta media, aunque algunos trabajadores catalogables como "grandes discapacitados físicos", puedan acreditar una elevada capacidad laboral. Otro tanto cabe señalar de los trabajadores afectados por discapacidad auditiva, incluidos dentro del bloque de los trabajadores con discapacidad sensorial, con un salario promedio de $2 \mathrm{I} .204$ euros pero que muy probablemente contarán con una retribución promediada inferior en atención a las carencias formativas que suelen afectar a las personas con discapacidad auditiva no sobrevenida. 
que hoy en día no disfrutan de bonificaciones, cuando fuesen formalizados con trabajadores afectados de especiales dificultades, ya que ello permitiría incentivar su contratación al tiempo que se subrayaría el criterio de la calidad en el empleo.

En lo que concierne a los trabajadores no afectados por especiales dificultades, cabe recordar que el diseño actual de las bonificaciones, basado en cantidades máximas en lugar de en porcentajes sobre la cuota empresarial, pone en riesgo la calidad en el empleo. A título de ejemplo, actualmente un trabajador varón con discapacidad física en grado de $40 \%$ y menor de 45 años generará una bonificación máxima de 375 euros al mes (4.500 euros al año) lo que claramente perjudica a los trabajadores con mayor retribución, ya que el tope previsto hace menguar la bonificación generada por la contratación de estos trabajadores cuanto más elevada sea su retribución ${ }^{24}$. Piénsese que con el sistema anterior la bonificación siempre iba en consonancia con el salario percibido, con el matiz de salarios que superasen la base máxima de cotización. Además, en perspectiva dinámica el actual diseño de la bonificación contiene un efecto perverso adicional: tenderá a frenar los aumentos salariales basados en la negociación individual, ya que en muchos casos tales aumentos no van a beneficiarse de bonificaciones en la cuota empresarial, lo que desincentivará las mejoras salariales y, por ende, la calidad en el empleo (Alemán y Grau, 20II: 36).

En fin, como se ha señalado más arriba, hoy en día las únicas transformaciones de contrato temporal en contrato indefinido que generan bonificaciones son las de los contratos de fomento del empleo de personas con discapacidad y las de contratos formativos. De

\footnotetext{
24. En algunos casos este planteamiento podría ser razonable ya que estaremos hablando de trabajadores con un notable atractivo para los empleadores: por su formación, competencia profesional, etc., razón por la que resulta comprensible topar el alcance de las bonificaciones. Sin embargo, desde una perspectiva de calidad en el empleo nos inclinamos por el viejo sistema de bonificaciones basadas en porcentajes, sobre los que no van a incidir los topes.
}

acuerdo con la línea operativa número 6.2 de la Estrategia Global, que preconiza, sin matices, favorecer la transformación de los contratos temporales en indefinidos, entendemos que lo razonable sería fomentar la transformación de todo tipo de contrato, lo que acabaría redundando en un mejor desarrollo profesional de los trabajadores con discapacidad vinculados mediante contrato por obra o contrato eventual $^{25}$.

\subsubsection{Bonificación por contratación temporal}

Más allá de los incentivos previstos para la contratación indefinida, la Ley prevé bonificaciones para la contratación temporal, con una cuantía y un alcance limitados, salvo en algunos casos de contratación formativa a los que nos referiremos al final de este apartado. De un lado, el artículo 2.2.4 de la Ley 43/2006 prevé que las personas con discapacidad insertadas mediante el contrato temporal de fomento del empleo (disposición adicional primera Ley 43/2006, con una duración entre uno y tres años), generarán una bonificación de 29I'66 euros mensuales (3.500 euros al año), cifra que se elevará hasta los 34 I'66 euros al mes (4.I0o euros al año) si el trabajador se encuentra entre los colectivos afectados por especiales dificultades. De acreditarse una edad igual o superior a los 45 años o bien la condición de mujer, la bonificación se incrementará en 50 euros mensuales, es decir, en 600 euros anuales, siendo acumulables las dos circunstancias lo que permitirá en su caso acceder a una bonificación mensual adicional de Ioo euros. La perspectiva de la calidad en el empleo justifica las diferencias de bonificación con los contratos fijos, si bien entendemos que para la contratación de trabajadores afectados por especiales dificultades, lo razonable habría sido, como mínimo, la extensión de una modesta bonificación para todo contrato temporal.

Sin olvidar que nos parecería más deseable, desde el punto de vista del fomento del

25. Sobre las bonificaciones a estos contratos, vid el siguiente apartado. 
empleo, que toda contratación de trabajadores afectados por especiales dificultades estuviese exenta de cotización; máxime teniendo en cuenta el régimen generalizado de exención disfrutado por los CEE para todo tipo de contratación. A este respecto, cabe apuntar dos consideraciones. La primera, que más allá de los contratos formativos, el único contrato temporal bonificado sea el contrato temporal de fomento del empleo de las personas con discapacidad constituye una circunstancia comprensible ${ }^{26}$ considerando las tradicionales reticencias del legislador a bonificar contratos temporales, siendo una opción coherente con la preferencia por la calidad en el empleo. Sin embargo, no debe olvidarse que los contratos temporales estructurales por obra o servicio y eventual son utilizados con frecuencia en procesos de inserción mediante empleo con apoyo $^{27}$, razón por la cual creemos que en base a los principios expresados por la Estrategia Global, sería conveniente y jurídicamente adecuado fijar bonificaciones a la contratación temporal estructural a tiempo completo y a tiempo parcial en el mercado ordinario de trabajo (Rubio, 2006: 7), cuando la persona con discapacidad forme parte de aquel colectivo. No en vano, el artículo 2 de la Ley 43/2006 prevé bonificaciones modestas -entre 4I'67 y 50 euros al mes- por todo tipo de

26. Piénsese que en este caso, se está garantizando una duración mínima de un año y una potencial extensión temporal hasta los tres años, lo que no sucede en el caso de los contratos temporales estructurales.

27. El documento "Datos de Empleo con Apoyo 20I I", ejemplar fotocopiado, facilitado por la Asociación Española de Empleo con Apoyo señala que entre los trabajadores que participaron en proyectos de empleo con apoyo durante $20 \mathrm{II}$, un total de 247 lo hicieron mediante contrato indefinido y I 86 mediante contrato temporal. Dada la moderada utilización del contrato temporal de la disposición adicional primera de la Ley 43/2006 (el único contrato temporal sujeto a bonificación junto a los formativos), sería adecuado prever alguna suerte de bonificación para los contratos temporales estructurales que se utilizan en el marco del apoyo. Al respecto, y en base a datos de las contrataciones efectuadas en noviembre de $20 \mathrm{I} 2$ se observa cómo los contratos de obra y servicio y eventuales suman I.7 I 2 contratos (un 32'62 de los contratos concertados) mientras que el contrato temporal no causal de uno a tres años alcanza la cifra de I.289 contratos ( $26{ }^{\prime} 23$ del total). Datos extraídos del documento "Información estadística sobre contratación de personas con discapacidad", (Situación a I de Diciembre de 20I2), elaborado por el Observatorio Estatal de la Discapacidad y consultable en <http://www.observatoriodeladiscapacidad.es $>$, acceso 30 de septiembre de 2013. contratación temporal otros colectivos de difícil empleabilidad: personas víctimas de violencia de género, de terrorismo, o personas en situación de exclusión social, lo que incluye la contratación a tiempo parcial. Ahora bien, bajo un criterio de potenciación de la calidad en el empleo, tales bonificaciones no deberían ser de aplicación a la contratación de trabajadores no afectados de especiales dificultades. Finalmente, en lo que concierne a la escasamente utilizada contratación formativa, cabe señalar que los contratos en prácticas disfrutan de una bonificación del 50\% de las cuotas empresariales a la Seguridad Social, mientras que los contratos para la formación y el aprendizaje permiten acceder a bonificaciones del $75 \%$ o del roo \%, lo que va a depender de si la empresa tiene menos de 250 trabajadores o 250 trabajadores o más (Ley 3/201 2, de 6 de julio, de medidas urgentes para la reforma del mercado laboral ${ }^{28}$ ).

\subsection{Requisitos y exclusiones en el acceso a las bonificaciones en materia de Seguridad Social}

\subsubsection{Requisitos de aplicación general}

En lo que concierne a los requisitos para acceder a las bonificaciones, estos vienen expresados sin especificaciones aparentes en el artículo 5 de la Ley 43/2006. Cabe detenerse de modo especial en el requisito previsto en el apartado a) en el que se señala la obligación empresarial de hallarse al corriente de sus obligaciones tributarias y de Seguridad Social tanto en la fecha del alta como durante la aplicación de las bonificaciones. De este modo, la falta de ingreso reglamentario de las cuotas patronales dará lugar a la pérdida automática de las bonificaciones por los periodos no ingresados en plazo $^{29}$.

Asimismo, el artículo 5.b de la Ley 43/2006 señala que podrían quedar excluidos totalmente del acceso a bonificaciones las empresas que

28. BOE, núm. I62, de 7 de julio de 2012.

29. Además, ese tiempo de no disfrute de bonificaciones será considerado como tiempo consumido para el plazo máximo de disfrute de la bonificación. 
incurran en infracciones muy graves en materia de empleo, exclusión que podría extenderse hasta los dos años ${ }^{30}$. Recuérdese además, que los empresarios que cometan infracciones en el cumplimiento del deber de reserva de empleo de personas con discapacidad (artículos I 5.3 y 46 bis I de la Ley sobre infracciones y sanciones en el orden social, aprobada mediante el Real Decreto Legislativo 5/2000, de 4 de agosto, por el que se aprueba el texto refundido de la Ley sobre Infracciones y Sanciones en el Orden Social $^{3 \mathrm{I}}$; en adelante LISOS), podrían ser excluidos del acceso a tales beneficios durante un periodo de dos años desde la fecha de la resolución que imponga la sanción. Téngase en cuenta que en este caso la infracción no es muy grave sino que solamente es grave, pero también se produciría la pérdida de acceso a nuevas bonificaciones.

De otra parte, la comisión de las infracciones señaladas en el párrafo anterior generará la pérdida de bonificaciones, de forma proporcional al número de trabajadores afectados por la infracción (artículo 46. I de la LISOS). De este modo, una infracción muy grave en materia de empleo que afecte a un trabajador generará la pérdida de bonificaciones disfrutadas por la contratación de otro trabajador y afectará de modo preferente a las bonificaciones de mayor cuantía que se perciban en la empresa.

Finalmente, la Ley 43/2006 no exige el requisito general de un determinado mantenimiento de volumen de empleo en la empresa para mantener las bonificaciones, como sucede en

30. En la práctica, esta exclusión en el acceso a bonificaciones de hasta dos años es de difícil aplicación, porque la Ley $43 / 2006$ se remite a las infracciones del artículo 46.2 de la LISOS mientras que tras algunas reformas, las infracciones muy graves en materia de empleo y la grave por incumplimiento de la reserva se mencionan ahora en el artículo 46.I de la LISOS. Esta circunstancia, por razones técnicas dificulta enormemente la aplicación de la exclusión. Para que la exclusión pudiese aplicarse, sería necesaria una remisión del artículo 5 de la Ley 43/2006 al artículo 46. I de la LISOS, cosa que ahora no sucede. Además, de acuerdo con el planteamiento de la Ley la exclusión no es automática, sino potestativa, dependiendo del criterio de la administración en base a las circunstancias. Así, se señala que los empleadores "podrán ser excluidos del acceso a tales beneficios"; no se dice que "quedarán excluidos". 3I. BOE, núm. I 89, de 8 de agosto de 2000 . otras normas de fomento de empleo. De este modo, el empresario no deberá preocuparse por las situaciones en las que se produzcan disminuciones en el volumen de plantilla de la empresa.

\subsubsection{Exclusiones de aplicación general}

En materia de exclusiones, afortunadamente el artículo 6.3 de la Ley 43/2006 no prevé la aplicación a las personas con discapacidad las exenciones previstas en las letras a) y b) del artículo 6 de la Ley 43/2006. Por lo tanto, disfrutarán de las bonificaciones las contrataciones efectuadas en el marco de relaciones laborales especiales, incluyendo lógicamente las concertadas entre persona con discapacidad y Centro Especial de Empleo, y también cuando concurran relaciones de parentesco entre empleador o responsable de la entidad empleadora y el trabajador con discapacidad $^{32}$. A este respecto, valoramos muy positivamente la no aplicación de estas exenciones a la contratación de personas con discapacidad, ya que por una parte ello podría dificultar la contratación cuando los trabajadores encuentren una oferta de empleo en un entorno regulado mediante régimen laboral especial, por ejemplo, en el ámbito del servicio doméstico. Del mismo modo, la no exclusión de las bonificaciones por razón de parentesco se nos antoja como un elemento clave, considerando al tiempo las dificultades en la empleabilidad de algunos trabajadores con discapacidad y el interés por que sus familias, o empresas vinculadas a su entorno familiar asuman su contratación como ya pasa en la práctica (Rubio, 2006: 8), mediando un cierto equilibrio de esfuerzos que puede lograrse mediante el disfrute de bonificaciones. No debe olvidarse, en fin, que este planteamiento encaja perfectamente

32. El artículo 6.I.b de la Ley 43/2006 excluye con carácter general de las bonificaciones a las "Contrataciones que afecten al cónyuge, ascendientes, descendientes y demás parientes por consanguinidad o afinidad, hasta el segundo grado inclusive, del empresario o de quienes tengan el control empresarial, ostenten cargos de dirección o sean miembros de los órganos de administración de las entidades o de las empresas que revistan la forma jurídica de sociedad, así como las que se produzcan con estos últimos”. 
en uno de los principios clave de la Estrategia Global, a saber, que los incentivos no supongan una barrera al desarrollo profesional de los trabajadores con discapacidad.

Por lo contrario, las bonificaciones disfrutadas a título de contratación de personas con discapacidad podrían verse afectadas por la exclusión prevista en el artículo 6.2 de la Ley 43/2006, en el sentido de que "Las empresas que hayan extinguido o extingan por despido reconocido o declarado improcedente o por despido colectivo contratos bonificados quedarán excluidas por un período de doce meses de las bonificaciones establecidas en este programa”. No obstante, la exclusión no será generalizada sino que únicamente afectará a un número de contratos igual al de las extinciones producidas $^{33}$.

\subsubsection{Exclusiones matizadas en el caso de contratación de personas con discapacidad}

El artículo 6.I.c de la Ley 43/2006 introduce dos exclusiones adicionales en el acceso a bonificaciones por la contratación de personas con discapacidad. La primera de ellas pretende evitar que las empresas que "recontraten" al mismo trabajador puedan aplicarse bonificaciones por segundas o ulteriores contrataciones, siempre bajo determinadas condiciones, planteamiento que a priori se nos antoja razonable. Concretamente, la Ley prohíbe la aplicación de beneficios a empresas que contraten a trabajadores que habían mantenido una relación de empleo indefinida con la misma empresa, grupo de empresas o entidad ${ }^{34}$ dentro de los veinticuatro meses inmediatamente anteriores a la nueva contratación. La misma prohibición se prevé cuando el trabajador hubiese estado vinculado a la empresa

33. Asimismo, la Ley clarifica que "el período de exclusión se contará a partir del reconocimiento o de la declaración de improcedencia del despido o de la extinción derivada del despido colectivo".

34. Señala la Ley (artículo 6.I.c, segundo párrafo) que esta exclusión será también aplicable a supuestos en que el trabajador hubiese estado vinculado a empresas "a las que el ssolicitante de los beneficios haya sucedido en virtud de lo establecido en el artículo 44 del Estatuto de los Trabajadores” dentro de los últimos seis meses mediante un contrato temporal, incluyendo los formativos, de relevo o de sustitución por jubilación ${ }^{35}$. En lo que concierne a esta exclusión, la Ley 43/2006 establece dos matices de gran interés práctico que beneficiarán a la contratación de trabajadores con discapacidad.

Así, de una parte, la exclusión no se aplicará en casos de previa contratación temporal del trabajador con discapacidad por la misma empresa, aplicándose esta excepción a la contratación de cualquier trabajador, sea cual sea el tipo o grado de discapacidad (artículo 6.3). A nuestro juicio se trata de una excepción razonable porque, se quiera o no, el contrato temporal representa un papel de periodo de prueba impropio, que en ocasiones va a facilitar la incorporación estable del trabajador tras su finalización, incorporación estable que, con esta regla, será bonificada ${ }^{36}$. Más interesante y muy razonable se nos antoja la segunda matización, según la cual la exclusión en el acceso a las bonificaciones no será en ningún caso aplicable cuando se pretenda la contratación de trabajadores afectados por especiales dificultades, previamente vinculados a la empresa. Para tales supuestos, su anterior vinculación con la empresa mediante contratación temporal o indefinida no impedirá que la nueva contratación genere bonificaciones. Entendemos que una razón de peso avalaría esta opción, ya que los zigzagueos laborales de las personas afectadas por especiales dificultades pueden tener su causa en abandonos laborales fruto de complicaciones sobrevenidas en su

35. No obstante, la Ley establece que no se aplicará la prohibición a supuestos de transformación de contratos temporales en contratos indefinidos, un caso para el que se aplicarían los artículos 2.6, 3 y 4.2 de la Ley. 36. En todo caso, cabe advertir que el paso sin solución de continuidad de un contrato temporal estructural -eventual, por obra o servicio, o por interinidad- al contrato indefinido no permite acceder a bonificaciones, ya que no nos hallaremos en un supuesto de transformación bonificable en el sentido de la Ley $43 / 2006$, por lo que sería necesario un mínimo espacio temporal -un día al menos- entre la extinción del contrato temporal y la posterior contratación indefinida. Se ha de recordar que solo dan lugar a contrato indefinido bonificado las transformaciones de contratos formativos o de contratos temporales para el fomento de la contratación de personas con discapacidad, -de uno a tres años de duración- de acuerdo con lo previsto en el artículo 2.2.I de la Ley 43/2006. 
discapacidad, de modo que si las dificultades se superan, se debe potenciar el retorno al anterior empleo mediante el disfrute de bonificaciones.

Una segunda exclusión, en la que se introducen importantes matices relacionados con la discapacidad, es la descrita en el artículo 6.I.d de la Ley, según la cual no generarán bonificaciones las contrataciones de trabajadores que "hayan finalizado su relación laboral de carácter indefinido en otra empresa en un plazo de tres meses previos a la formalización del contrato" por decisión personal. La exclusión no operará cuando la finalización del contrato derive de despido reconocido o declarado improcedente o de despido colectivo, de manera que se pretende evitar la incentivación de la contratación de trabajadores que previamente han dimitido voluntariamente de su trabajo anterior. Lógicamente, no parece razonable incentivar el empleo de aquella persona que ha perdido voluntariamente su ocupación anterior. Pues bien, en caso de contratación de personas con discapacidad, esta exclusión no será de aplicación en dos supuestos.

Con carácter general no se aplicará en la contratación de trabajadores afectados por especiales dificultades, lo que se nos antoja muy adecuado ya que entendemos que debe preservarse de modo especial las mejoras de empleo de estos trabajadores, siguiendo la lógica de no obstaculizar el desarrollo profesional, mencionada en la Estrategia Global. De otra parte y para los supuestos en los que no se trate de trabajadores afectados por especiales dificultades, la Ley establece excepciones adicionales que están relacionadas, en general, con la transición de los trabajadores con discapacidad que trabajen en CEE y con el derecho de retorno de estos mismos trabajadores. De este modo, el artículo 6.3 de la Ley señala que esta exclusión no será de aplicación a los supuestos de contratación por la empresa ordinaria, de trabajadores con discapacidad procedentes de CEE. Tampoco será de aplicación a supuestos de retorno al empleo protegido, tanto si el retorno laboral se hace efectivo en el CEE de procedencia, como si se produce en otro Centro Especial.
En general, el planteamiento nos parece de todo punto razonable desde la perspectiva de la calidad en el empleo como desde el punto de vista de fomentar la transición hacia el mercado ordinario de trabajo: principio general clásico, mantenido en por el artículo 43.I LGDPD sin olvidar el interés por la promoción, mejora o “desarrollo profesional”, mencionado en la Estrategia Global. A ese respecto, cabe subrayar la coherencia de la Ley 43/2006 con diversas líneas de actuación de la Estrategia Global como las indicadas en el apartados 5.7, que recoge el derecho de retorno, y en el apartado 5.8 donde se proponía la promoción del tránsito del empleo protegido al empleo ordinario.

Finalmente, debemos recordar que la Ley 43/2006 prevé una excepción adicional ya que la exclusión tampoco será de aplicación (artículo 6.3) cuando se produzca la incorporación de trabajadores a empresas ordinarias en el marco del programa de empleo con apoyo. Ciertamente, se trata de una excepción razonable pero en general innecesaria porque la inmensa mayoría de trabajadores insertados mediante apoyo son trabajadores afectados por especiales dificultades, definidos por la propia Ley 43/2006 (artículo 6.3, inciso final) y por ello quedarían exceptuados con carácter general de la exclusión prevista en la Ley. Ahora bien, excepcionalmente puede haber trabajadores que no son catalogables formalmente como afectados de especiales dificultades pero que pueden requerir apoyo; fundamentalmente, personas afectadas de sordera con una discapacidad inferior al $65 \%$. Para estos casos, la previsión de la Ley 43/2006 tiene un notable sentido ya que el cese en una empresa ordinaria y el paso a otra empresa ordinaria, en perspectiva de mejora de empleo, no impediría que la empresa "de llegada" pudiese acceder a bonificaciones, precisamente porque el

37. Recuérdese que la disposición adicional primera del Real Decreto $870 / 2007$, de 2 de julio, por el que se regula el programa de empleo con apoyo como medida de fomento de empleo de personas con discapacidad en el mercado ordinario de trabajo, $B O E$, núm. I 68 , de I 4 de julio de 2007 , prevé que las personas con discapacidad auditiva no inferior al $33 \%$ y que no alcancen el grado del $65 \%$ tendrán la consideración de persona con discapacidad física del $65 \%$ (artículo $7 \mathrm{c} \mathrm{del}$ Decreto) a fin y efecto de beneficiarse del empleo con apoyo. 
trabajador efectuará la transición en un marco de empleo con apoyo. Por lo demás, avalarían esta opción la fidelidad a la línea de actuación 4.9 de la Estrategia Global, y en especial la necesidad de evitar barreras al desarrollo profesional.

3. Las subvenciones económicas directas en el marco del empleo de las personas con discapacidad

Las subvenciones económicas directas se prevén en los artículos 7 y I 2 del Real Decreto I 45 I $/$ I $983^{38}$, y su finalidad es la integración plena y efectiva de las personas con discapacidad, actuando a través de la intervención, estatal y autonómica, "directamente en la oferta y demanda de empleo, venciendo las resistencias iniciales a la contratación” (Lahera, 2005: 95).

El legislador estableció dos tipos de subvenciones: a) Subvención por contrato realizado a personas con discapacidad; b)

38. En un primer momento, la Disposición derogatoria única apartado segundo de la Ley 43/2006 establece la derogación de las referencias a las bonificaciones en las cuotas empresariales a la Seguridad Social por la contratación de trabajadores con discapacidad establecidas, entre otras, en el Real Decreto I45I/I983.

La Disposición derogatoria única apartado r.a del Real Decreto-Ley 3/20II, de I 8 de febrero incluyó, de nuevo, la derogación del capítulo II (artículos 7 a I4) del Real Decreto I 45I/I983.

Ahora bien, la disposición derogatoria única I.h del Real Decreto-Ley $3 / 20$ I 2 , de Io de febrero, de medidas urgentes para la reforma del mercado laboral (BOE, núm. 36 de I 2 de febrero de 20I2), establece la derogación expresa de la disposición derogatoria única del Real Decreto-ley 3/20I I, de I 8 de febrero, de medidas urgentes para la mejora de la empleabilidad y la reforma de las políticas activas de empleo (BOE, núm. 43 , de I9 de febrero de $20 \mathrm{II}$ ), entre otras, que contemplaba la derogación, entre otras, del capítulo II (artículos 7 a I4) del Real Decreto I45 I/I983.

La vigencia y derogación de la norma, en los términos precisados, puede constatarse en el apartado análisis de la página web del BOE en la que consta la aprobación de la norma: <http://www.boe.es/diario_boe/txt.php?id=BOE-AI983-I 58 I 3 \# analisis $>$.

Por lo tanto, el artículo 7 del Real Decreto I45I/I983 se encuentra, actualmente, en vigor.
Subvención destinada a la adaptación de los puestos de trabajo, o dotación de equipos de protección personal necesarios para evitar accidentes laborales al trabajador con discapacidad contratado, o para eliminar barreras u obstáculos que impidan o dificulten el trabajo de los trabajadores con discapacidad.

La creación de tales incentivos se fundamenta en el artículo 49 C.E. cuyo objetivo es eliminar "todos los obstáculos para alcanzar una igualdad sustancial de oportunidades en el acceso al empleo" (Lahera, 2005: 95 ).

El ordenamiento laboral ha asumido el mandato constitucional a través del artículo I7.3 TRLET y 39.2 LGDPD, los cuales contemplan el fomento del empleo de este colectivo mediante el establecimiento de ayudas que faciliten su inclusión laboral.

Con carácter preliminar, hemos de señalar que algunas CCAA no están convocando en los últimos tiempos estas ayudas, alegando insuficiencia presupuestaria, que también afecta a las subvenciones salariales de los CEE. La situación no es generalizada ${ }^{39}$ pero es lo suficientemente grave como para que se activen las estrategias necesarias que no dejen desactivadas medidas muy relevantes a fin de incentivar una inserción de calidad en entornos ordinarios. Por ello más que nunca se ha de reivindicar la línea operativa de la Estrategia Global que preconizaba la suficiencia financiera para garantizar los incentivos a la contratación en el mercado ordinario de trabajo.

\subsection{Subvención por contrato realizado a personas con discapacidad}

\subsubsection{Características básicas}

El artículo 7 del Real Decreto I45I/I983, establece la existencia de una subvención

39. Como se ha señalado en un punto anterior y según información del Departamento de Empresa y Empleo de la Generalitat de Cataluña desde hace dos años no se convocan las subvenciones económicas a la contratación en la empresa ordinaria ni las dirigidas a la adaptación de puesto de trabajo. 
destinada a las empresas que contraten personas con discapacidad, cuya cuantía asciende a 3.907 euros por trabajador con discapacidad contratado. Dicha contratación deberá ser indefinida, ya sea a tiempo completo o a tiempo parcial $^{4}$.

El momento de cumplimiento de los requisitos definidos legalmente es, según reiterada doctrina judicial ${ }^{4 \mathrm{r}}$, el momento previo a la contratación, pues "[...] solo de esa manera queda cumplido el fin de la ayuda pública que es fomentar el empleo de minusválidos inscritos en el INEM a tales fines".

Paralelamente, las empresas que se beneficien de la concesión de esta subvención tienen la obligación de mantener en sus plantillas a los trabajadores contratados durante un periodo mínimo de tres años, prohibiéndose de forma expresa despedir sin causa justificada a estos trabajadores, ya que en caso de despido improcedente deberán devolver íntegro el importe de la subvención.

Para casos de despido procedente el empresario deberá contratar a otro trabajador con discapacidad, sin que tenga derecho a volver a percibir la subvención, so pena de devolver íntegramente ${ }^{42}$ los importes percibidos al

40. La posibilidad de conceder la subvención a aquellas empresas que contratasen trabajadores con discapacidad a tiempo parcial, con la correspondiente prorrata proporcional a la jornada efectivamente pactada ex artículo 7.I in fine, no se incluyó ab initio en la redacción del Real Decreto I45I/I 983. Tuvieron que pasar I 6 años, en concreto hasta la aprobación del Real Decreto 4/I999 de 8 de Enero, para que el legislador incluyera dicha posibilidad, motivándose tal actuación, según el preámbulo de dicha norma, en "[...] las experiencias positivas que se generaron al amparo del Real Decreto I45I/I983, $[\ldots]$...

4I. Vid. Sentencia del Tribunal Superior de Justicia de Asturias (Sala de lo Contencioso-Administrativo) núm. 20/I998, de Io

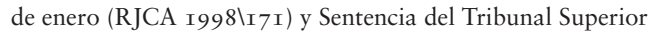
de Justicia de Castilla y León, Valladolid (Sala de lo Contencioso-Administrativo) núm. I $807 / 2005$, de I de septiembre (RJCA 2005\710), entre otras.

42. La devolución de la subvención es una facultad sometida al plazo de prescripción de cuatro años previsto según el artículo I 5.I de la Ley 47/2003, de 26 de noviembre, General Presupuestaria, tal y como se ha manifestado por la doctrina judicial. En este sentido, la Sentencia del Tribunal Superior de Justicia de Castilla La Mancha (Sala de lo Contencioso-Administrativo) núm. 686/I998, de 3 I de julio (RJCA I998\2959) fija en su Fundamento de Derecho I que el plazo a tener en amparo del artículo ro in fine del Real Decreto I 45 I/I 983 .

No obstante, la penalización prevista por el legislador podrá ser objeto de modulación por los tribunales atendiendo a la equidad, tal y como ha señalado la doctrina de la Sala de lo Contencioso Administrativo del Tribunal Supremo ${ }^{43}$. Así, en casos de despido procedente, la imposibilidad de contratar a otro trabajador con discapacidad llevará a la obligación de devolver, únicamente, la parte proporcional de los tres años no cubierta con una contratación de persona con discapacidad.

En este orden de cosas, la obligación de contratar a un nuevo trabajador con discapacidad sustituto también se extiende a aquellos supuestos de cese voluntario del trabajador con discapacidad contratado inicialmente, tal y como se ha reconocido en sede judicial ${ }^{44}$. Esta conclusión jurídica parte de la voluntad con la que se ha concebido la subvención, que no es otra que garantizar la estabilidad en el empleo de las personas con discapacidad. Ello supone que, en previsión de una aplicación fraudulenta de la disposición, se considere que deba procederse, en caso de cese voluntario del trabajador, a “[...] su sustitución por otro como si de un despido procedente se tratara".

Como puede observarse, la rigidez del requisito de sustituir al trabajador en cualquier supuesto de cese del mismo se convierte en un obstáculo cuando la búsqueda de un trabajador con perfil similar al inicial se demora en el tiempo.

Ello se agrava con la inexistencia de obligación por parte del Servicio Público de Empleo de proporcionar trabajadores adecuados según ha

cuenta para la prescripción del derecho de la Hacienda Pública al cobro de créditos a su favor es el previsto en el artículo 40 de la hoy derogada Ley I I/I977, de 4 de enero, General Presupuestaria.

43. Vid. Sentencia del Tribunal Supremo (Sala de lo Contencioso-Administrativo) de I4 de febrero de I997 (RJ I997/I094).

44. Vid. Sentencia del Tribunal Superior de Justicia de La Rioja (Sala de lo Contencioso-Administrativo) núm. 73/1997, de Io de febrero (RJCA I997\349), en la cual se analiza esta cuestión en su Fundamento de Derecho II. 
sostenido la doctrina judicial ${ }^{45}$, atendiendo a la falta de previsión legislativa sobre este extremo.

Finalmente, las exclusiones previstas en el artículo 6 de la Ley 43/2006 no se aplican a esta subvención en tanto que su regulación no se encuentra en el programa de fomento del empleo contenido en la citada norma.

\subsubsection{Cuestiones aplicativas de interés general}

\section{A. La cuantía de la subvención}

La primera de las cuestiones es la relativa a la cuantía de la subvención y su periodo de disfrute. A primera vista puede parecer relativamente elevada, pues se confiere por la mera contratación del trabajador/a con discapacidad, pero la exigencia de mantener la contratación durante un periodo mínimo de tres años, parece excesiva para fomentar la contratación del colectivo, teniendo en cuenta que proyectada sobre 36 meses, el incentivo mensual asciende a 108,52 euros.

La flexibilización de este requisito es una modificación que debe llevarse a cabo con urgencia, en tanto que supone la desaparición de la eficacia del incentivo una vez transcurridos 36 meses y es contraria con la propia finalidad de la subvención, que pretende fomentar la contratación indefinida de trabajadores con discapacidad.

En consecuencia, el legislador debe extender el disfrute del incentivo a toda la vigencia del contrato, creando a tal efecto dos regímenes jurídicos: uno para los contratos indefinidos y otro para los contratos temporales.

La incentivación de la contratación indefinida debe extenderse a toda la duración de la relación laboral y una cuantía más elevada, contemplándose la devolución de las cantidades percibidas en caso de extinciones o despidos declarados improcedentes.

45. Vid. Sentencia del Tribunal Superior de Justicia de Castilla-La Mancha núm. 686/I998, de 3 I de julio (RJCA I998\2959).
En cuanto al régimen propuesto para la contratación temporal, la percepción de la subvención se extendería durante la permanencia del contrato de trabajo y su cuantía debería ser inferior al importe previsto en caso de contratación indefinida.

La devolución íntegra de la cuantía percibida únicamente deberá realizarse si judicialmente se declara fraude en el contrato o la improcedencia de la extinción.

Estas modificaciones permitirían eliminar maniobras jurídicas encaminadas únicamente al disfrute de la subvención. En este sentido, la previsión de un mayor importe para el contrato indefinido se justifica por el fomento de la contratación, la calidad en el empleo y el mantenimiento del empleo, a diferencia del régimen temporal que, por su duración, no genera efectos tan intensos en los objetivos que persigue la subvención.

\section{B. La actualización de la cuantía}

La segunda de las cuestiones de interés es la necesidad de actualizar la cuantía de la subvención por contrato realizado.

La cantidad prevista inicialmente $(500.000$ pesetas) sólo ha sido objeto de ampliación una vez, en la que se incrementó la cuantía a 650.000 pesetas, esto es, los actuales 3.907 euros.

Sorprende cuanto menos que el legislador no se haya preocupado de actualizar dicha cuantía, como mínimo, conforme al incremento anual del $\mathrm{IPC}^{46} \mathrm{y}$, más aún, que solo se haya actualizado una vez la cuantía de la subvención, tomando como referencia para ello un lapso temporal excesivamente amplio (I 5 años).

Ello repercute negativamente en el impacto integrador de la subvención, y por ende, en

46. La variación del Índice General de Precios al Consumo desde enero I 999 hasta enero 2013 asume la cifra de 47,3 puntos porcentuales 
la integración efectiva de las personas con discapacidad, pues la instrumentación de la subvención en su momento (I983) no se ha acompañado de ninguna modificación o creación de medidas incentivadoras complementarias.

Las consecuencias se traducen en la pérdida de protagonismo del incentivo como mecanismo de integración, pues año a año la cuantía se ha reducido con el impacto del aumento de los precios al consumo.

\section{El concepto de persona con discapacidad}

La tercera cuestión viene referida al concepto de persona con discapacidad al que se refiere el Real Decreto I45I/I983, para la concesión de la subvención objeto de estudio.

El legislador ha instaurado un sistema de determinación y reconocimiento de discapacidad, que tiene en cuenta la diversidad existente de afectaciones físicas ${ }^{47}$ y psíquicas ${ }^{48}$ y factores sociales complementarios ${ }^{49}$; pero tal reconocimiento no se ha traducido en la acomodación de las cuantías de la subvención en función del grado o clase de discapacidad.

El criterio por el que se ha optado, consistente en encuadrar como personas con discapacidad a aquellas que dispongan de un reconocimiento de un $33 \%$ o más, es pobre y excesivamente generalista. La vaguedad del planteamiento asumido no genera efectos positivos en aquellas personas con discapacidad con especiales dificultades para su inserción laboral.

Además, "la delimitación porcentual del concepto genera situaciones de injusticia material en las franjas más cercanas al límite

47. Vid. Capítulo 2 a I 3 del Anexo I.A del Real Decreto I97I/I999, entre las cuales se incluyen sistema músculo esquelético, sistema nervioso, aparato respiratorio, aparato cardiovascular, entre otros.

48. Vid. Capítulo I 4 a I 6 del Anexo I.A del Real Decreto I97I/I999.

49. Vid. Anexo I.B del Real Decreto I97I/I999, de 23 de diciembre. porcentual, de modo que una mínima diferencia en la discapacidad provoca en un trabajador el reconocimiento de una condición que merece abundante protección o bien la negación absoluta de tal derecho" (Pérez, 2008: $32 \mathrm{I}$ ).

El legislador no es ajeno a esta cuestión, pues la Estrategia Global ${ }^{\circ}$ prevé como objetivos "modular los incentivos según el tipo y grado de discapacidad", pero sus actuaciones al respecto han sido, en esta materia, inexistentes.

En consecuencia, deben reformularse las cuantías a conceder en concepto de subvención por contrato realizado a persona con discapacidad, teniendo en cuenta para ello el grado de discapacidad y las posibilidades de integración de la persona. Y en concreto, debe ampliarse el quantum a conceder a aquellas personas con mayores dificultades de inserción en el ámbito de empleo ordinario.

\subsubsection{Cuestiones aplicativas de especial interés: Régimen de compatibilidad entre la subvención estatal y las subvenciones autonómicas por contrato realizado con personas con discapacidad}

La existencia de un marco estatal y un marco autonómico en materia de incentivos a la contratación de personas con discapacidad exige analizar la configuración actual de las subvenciones autonómicas previstas a tal efecto.

Este examen requiere identificar el papel de las CCAA en el fomento del empleo de las personas con discapacidad y determinar sí existe posibilidad de compatibilizar su concesión con la subvención estatal.

Asimismo, también se estudia en este apartado la utilización, por parte de las CCAA, de la facultad de desarrollar políticas de empleo en

50. El objetivo 4, que pretende "Promover una mayor contratación de personas con discapacidad en el mercado de trabajo ordinario", incluye como principio en su apartado c), relativo a los incentivos a la contratación, la "posibilidad de modular los incentivos según el tipo y el grado de discapacidad, el sexo y la edad". 
materia de trabajadores con discapacidad, lo cual incluye el establecimiento de incentivos a la contratación, posibilidad ésta prevista en el artículo 25.I.f de la Ley 56/2003, de I6 de Diciembre, de Empleo ${ }^{51}$ (en adelante, Ley $56 / 2003)$.

Como punto de partida, la integración laboral de las personas con discapacidad se incardina en el artículo I49.I.7 C.E., y por lo tanto, pertenece exclusivamente al Estado, "sin perjuicio de la posible gestión administrativa de las distintas medidas estatales por parte de las CCAA" (Lahera, 2005: 93).

No obstante, la intervención de las CCAA es posible al amparo del artículo I48.I.I3 C.E., que prevé "el fomento del desarrollo económico de la Comunidad Autónoma dentro de los objetivos marcados por la política económica nacional".

Esta tesis ha sido confirmada por la doctrina (López, 2004: 4-95; y Cordero, 20II: 254), que ha sostenido que el mandato constitucional de realizar una "política orientada al pleno empleo" se dirige a todos los poderes públicos, entre los que se incluyen lógicamente las CCAA.

Paralelamente, el papel de éstas ha sido reforzado con la creación de los servicios públicos de empleo autonómicos, al amparo de los artículos 17 y siguientes de la Ley $56 / 2003$, lo cual ha materializado el traspaso del "ejercicio de las funciones necesarias para la gestión de la intermediación laboral [...] y de las políticas activas de empleo [...]" ${ }_{52}$.

En este sentido, el artículo 25.r.f de la Ley 56/2003 faculta la intervención de las CCAA en el ámbito de las políticas activas de inserción de personas con discapacidad, identificando la incentivación de la contratación en el empleo ordinario, entre otros, como uno de los campos

5I. BOE, núm. 30I, de I7 de diciembre de 2003. 52. Vid. Artículo I 7 de la Ley 56/2003, de I6 de diciembre, que remite a los artículos 20 y siguientes de la citada norma en materia de intermediación laboral, y a los artículos 23 y siguientes en cuanto al ejercicio de funciones en relación a políticas activas de empleo. en los que se permite su actuación. El único límite al que se hallan sometidas es la no invasión de competencias del Estado en materia de legislación laboral y de Seguridad Social (López, 2004: 97).

En este orden de cosas, el legislador admite de forma acertada la acumulación de la subvención estatal y las subvenciones autonómicas por la contratación de personas con discapacidad, siempre que no se supere el $60 \%$ del coste salarial anual correspondiente al contrato que genera el derecho. Este porcentaje, previsto por el artículo 7.3 del Real Decreto I45I/I983, debe flexibilizarse en función del tipo y grado de discapacidad, sexo y edad del trabajador contratado. Las razones que lo justifican parten de una visión coherente con la Estrategia Global, que identifica como principio inspirador en el apartado c) del objetivo 4 la posibilidad de "modular los incentivos según el tipo y el grado de discapacidad, el sexo y la edad".

Tal modificación permitiría adecuar los límites a la percepción de subvenciones por contratación de personas con discapacidad en función de las posibilidades de inserción laboral del trabajador con discapacidad.

Definidos los términos en los que opera la compatibilidad de la subvención estatal y las subvenciones autonómicas, corresponde examinar en detalle el marco autonómico. Una primera observación que debe señalarse es la disparidad numérica respecto a la tipología de los programas de fomento de empleo destinados a personas con discapacidad previstos autonómicamente.

La mayoritaria presencia de las ayudas destinadas a $\mathrm{CEE}^{53}$, muy por encima

53. Una buena muestra de ello la observamos en los distintos boletines oficiales de las distintas CCAA. En concreto, la Orden de 2 I de junio de 2013 por la que se establecen las bases reguladoras de los programas para la promoción de la integración laboral de las personas con discapacidad en centros especiales de empleo y de subvenciones a las unidades de apoyo a la actividad profesional en el marco de los servicios de ajuste personal y social de los centros especiales de empleo, cofinanciado por el Fondo Social Europeo, y se procede a su convocatoria para el año 20I3 (Galicia); Resolución de 26 de 
numéricamente de otras ayudas previstas a empresas de inserción, al empleo con apoyo y al empleo ordinario, evidencia que las CCAA no focalizan su atención en aquellas ayudas destinadas al empleo ordinario.

En segundo lugar, la configuración utilizada por las autonomías es muy aproximada a la prevista por el artículo 7.I del Real Decreto I45I/I983. Las diferencias entre las subvenciones autonómicas y la subvención estatal las hallamos principalmente en dos campos: la cuantía y su diferencia en función de las circunstancias personales (sexo, tipo de discapacidad y porcentaje de discapacidad).

Respecto a la cuantía, se observa que las CCAA incrementan la cuantía prevista para las subvenciones contenidas en programas de fomento del empleo de las personas con discapacidad. En este sentido, del total de las CCAA ${ }^{54}$ que prevén la existencia de

agosto de 2013 , de la consejería de economía y empleo, por la que se aprueban las bases reguladoras de la concesión de subvenciones a la inserción laboral de las personas con discapacidad en los centros especiales de empleo (Asturias); Orden de 28 de junio de 2013 , del Consejero de Economía y Empleo, por la que se convocan para 2013 subvenciones para proyectos generadores de empleo para personas con discapacidad en Centros Especiales de Empleo (Aragón); Orden 4370/2013, de I 8 de julio, de la Consejería de Empleo, Turismo y Cultura, por la que se modifica la Orden I $857 / 2008$, de II de julio, de la Consejería de Empleo y Mujer, y se convocan subvenciones para el fomento de la integración laboral de personas con discapacidad en Centros Especiales de Empleo (coste salarial) en el año 20I3 (Madrid); Orden EYE/IO96/20I2, de I 8 de diciembre, por la que se convocan subvenciones destinadas a la financiación de los costes salariales de los trabajadores con discapacidad en Centros Especiales de Empleo para el año 2013 (Castilla y León), entre otras.

54. El total de CCAA son seis: Cantabria (Orden HAC/23/20I3, de $I_{3}$ de mayo de $20 \mathrm{I}_{3}$, por la que se establecen las bases reguladoras y se aprueba la convocatoria de subvenciones destinadas a incentivar la contratación indefinida de personas en situación de desempleo); Castilla La Mancha (Orden de 30/07/2013, de la Consejería de Empleo y Economía, por la que se aprueba la convocatoria para el ejercicio 2013 de las ayudas establecidas en el Decreto 39/20I3, de I I de julio, por el que se regula los incentivos destinados a fomentar la contratación de las personas con discapacidad en el mercado ordinario de trabajo de Castilla-La Mancha); Islas Baleares (Resolución del Consejero de Economía y Competitividad de I 7 de mayo de 2013 por la que se aprueba la convocatoria para conceder ayudas sobre el fomento del empleo de las personas con discapacidad que establece el Capítulo II del Real Decreto I45I/I983, de I I de mayo); Navarra (Resolución 795/2013, de I6 de mayo, de la Directora Gerente del Servicio Navarro de Empleo, por la que se aprueba la con- subvenciones para la contratación de personas con discapacidad para el año 20I3, la mayoría de ellas aumentan las cantidades fijadas por la subvención estatal.

Por ejemplo, en el caso de Cantabria, el artículo 5.3 de la Orden HAC/23/20I3, de I3 de mayo por la que se establecen las bases reguladoras y se aprueba la convocatoria de subvenciones destinadas a incentivar la contratación indefinida de personas en situación de desempleo ${ }^{55}$, establece, en relación al colectivo "Personas con discapacidad", la cantidad de 4.000 euros en concepto de subvención por contratación a tiempo completo.

Castilla-La Mancha también prevé una mejora respecto de las cantidades previstas de forma estatal, pues el artículo I 3 del Decreto 39/2013, de I I de julio, por el que se regula los incentivos destinados a fomentar la contratación de las personas con discapacidad en el mercado ordinario de trabajo de Castilla-La Mancha ${ }^{56}$ fija como importe de la subvención 3.907 euros, cantidad a la cual debe sumarse un importe correspondiente a una ayuda adicional en función de las circunstancias de la persona en cuestión, cantidad esta que oscila entre los I.000 y 2.000 euros.

vocatoria de subvenciones para favorecer la inserción laboral de personas con discapacidad en el mercado ordinario de trabajo); Valencia (ORDEN I3/20I3, de 2 I de mayo, de la Consejería de Industria, Comercio, Turismo i Empleo, por la que se convoca y regula la concesión de subvenciones públicas destinadas al fomento del empleo para personas con discapacidad en el ejercicio de 2013) y Extremadura (Orden de 6 de agosto de 2013 por la que se convoca la concesión de incentivos destinados a favorecer la contratación de personas con discapacidad en el mercado ordinario de trabajo en la Comunidad Autónoma de Extremadura para el ejercicio 2013).

Paralelamente, existe el caso de Murcia, la cual aprobó las bases reguladoras de los programas de subvenciones para el fomento de la integración laboral de personas con discapacidad correspondiente al ejercicio 20I3, mediante la Orden de Io de julio de 2013, del Presidente del Servicio Regional de Empleo y Formación, de bases reguladoras de los programas de subvenciones para el fomento de la integración laboral de personas con discapacidad, pero cuyo programa destinado a la integración de las personas con discapacidad en el ámbito ordinario aún no se ha instrumentado. 55. BOCA, núm. 98, de 24 de mayo de 2013. 56. DOCM, núm. I37, de I7 de julio de 2013. 
La comunidad autónoma de Islas Baleares opta igualmente por la mejora de las cuantías, y prevé en el artículo 7.I de la Resolución del Consejero de Economía y Competitividad de I 7 de mayo de $20 \mathrm{I}_{3}$, por la que se aprueba la convocatoria para conceder ayudas sobre el fomento del empleo de las personas con discapacidad que establece el Capítulo II del Real Decreto I 451/1983, de I I de mayo ${ }^{57}$, donde se prevé como importe de la subvención para el fomento del empleo de las personas con discapacidad la cantidad de 3.907 euros.

Otro caso significativo es el de Navarra, que fija en el artículo 6 de la Resolución 795/20I3, de I 6 de mayo, de la Directora Gerente del Servicio Navarro de Empleo, por la que se aprueba la convocatoria de subvenciones para favorecer la inserción laboral de personas con discapacidad en el mercado ordinario de trabajo ${ }^{58}$, como mínimo 4.000 euros (persona con discapacidad hombre) y como máximo 8.400 euros (persona con discapacidad mujer con especiales dificultades de acceso al mercado ordinario de trabajo).

El planteamiento de la Comunidad Valenciana, previsto en el artículo 3 I.I y 32.I de la Orden I3/20I3 de 2 I de mayo, de la Consejería de Economía, Industria, Turismo y Empleo, por la que se convoca y regula la concesión de subvenciones públicas destinadas al fomento del empleo para personas con discapacidad en el ejercicio 20I $3^{59}$, merece especial indicación, pues identifica un marco de cuantías que varían en función del porcentaje y tipo de discapacidad, y cuyos importes oscilan entre los 3.500 y los 5.000 euros.

El caso de Extremadura es otro de los que merecen especial atención. Esta Comunidad Autónoma aprobó, mediante el Decreto I 49/20I 2, de 27 de julio, por el que se regulan los incentivos destinados a favorecer la contratación de personas con discapacidad en el mercado ordinario de trabajo y se aprueba la primera

57. BOIB, núm. 77, de I de junio de 2013.

58. BON, núm. I02, de 30 de mayo de 2013. 59. DOCV, núm. 7036, de 3 I de mayo de 2013. convocatoria de dichas subvenciones ${ }^{60}$, un ambicioso programa de subvenciones dividido en cinco modalidades ${ }^{61}$, para los ejercicios 20I 2-20I 5 . En este contexto, se aprobó la Orden de 6 de agosto de $20 \mathrm{I}_{3}$, por la que se convoca la concesión de incentivos destinados a favorecer la contratación de personas con discapacidad en el mercado ordinario de trabajo en la Comunidad Autónoma de Extremadura para el ejercicio $2013^{62}$, que prevé, en su artículo 7, como cuantías: a) para la subvención para la contratación indefinida de las personas con discapacidad la cantidad de 7.000 euros por contrato; b) para la transformación de distintos contratos en indefinidos la cantidad de 4.500 euros por contrato; $y, c)$ para la contratación temporal la cantidad de I.000 euros por contrato.

Finalmente, Murcia contempla asimismo, en el artículo 67 de la Orden de Io de julio de $2013^{63}$, una cuantía de hasta 2.400 euros, ampliándose hasta 3.400 si el trabajador contratado proviene de los subprogramas correspondientes a "enclaves laborales", "empleo con apoyo" o "gabinetes de orientación laboral".

No obstante, el aumento de las cantidades respecto a la subvención estatal pierde

\footnotetext{
6o. DOE, núm. I 49, de 2 de agosto de 20 I 2. 6I. El citado programa prevé:

- Programa I: Subvenciones para la contratación indefinida de las personas con discapacidad desempleadas en empresas ordinarias, o la incorporación de trabajadores con discapacidad como socios trabajadores en caso de Sociedades Cooperativa de Trabajo Asociado y Sociedades Laborales.

- Programa II: Subvenciones para la contratación indefinida por empresas ordinarias de trabajadores discapacitados con especiales dificultades de integración laboral procedentes de los enclaves laborales.

- Programa III: Subvenciones destinadas a la transformación de contratos temporales de fomento del empleo, contratos en prácticas, o para la formación, de relevo y de sustitución por anticipación de la edad de jubilación en indefinidos celebrados con trabajadores con discapacidad, en indefinidos celebrados con trabajadores con discapacidad.

- Programa IV: Subvenciones para la contratación temporal de fomento del empleo de trabajadores con discapacidad en empresas ordinarias.

- Programa V: Subvenciones para la adaptación del puesto de trabajo, dotación de medios de protección personal o eliminación de barreras arquitectónicas

62. DOE, núm. I 57, de I4 de agosto de 20I3.

63. BORM, núm. I63, de I 6 de julio de 2013.
} 
virtualidad a tenor del límite del $60 \%$ del coste anual previsto para el trabajador en cuestión según el artículo 7.3. del Real Decreto I 45 I/I983.

Como apunte final, merece la pena destacar el planteamiento que realizan la Comunidad Valenciana, Navarra o Castilla-La Mancha, que diferencian en función del sexo, del tipo de discapacidad y del porcentaje, enriquece la eficacia incentivadora del programa de fomento del empleo, ya que permite una mejor adaptación a las circunstancias de cada trabajador, y en último término, maximizar el fomento del empleo para aquellas personas con discapacidad con mayores dificultades de inserción laboral.

\subsection{Subvención destinada al fomento de la contratación y adaptación de puestos de trabajo de personas con discapacidad}

\subsubsection{Conceptualización y cuestiones aplicativas de interés}

El artículo I 2 del Real Decreto I45I/I983, prevé una subvención cuyo objeto se desdobla en tres alternativas posibles; la adaptación de puestos de trabajo, la dotación de equipos de protección personal o la eliminación de barreras u obstáculos que impidan o dificulten el trabajo de las personas con discapacidad.

Su concesión se limita a aquellas empresas que contraten personas con discapacidad, permitiendo la compatibilidad de ésta con la percepción de la subvención por contrato realizado.

Llama poderosamente la atención que la norma contemple la posibilidad de que el trabajador, de forma subsidiaria, pueda pedir la citada subvención si la empresa no la solicitase, máxime cuando la obligación de adaptación del puesto de trabajo ha sido atribuida, como no puede ser de otra manera, al empresario en virtud del artículo 40.2 LGDPD.

La cuantía de la subvención se halla en el artículo I.2 de la Orden, de I 3 de abril de I994, por la que se regula la concesión de las ayudas y subvenciones sobre fomento del empleo de los trabajadores minusválidos, que establece el capítulo II del Real Decreto I45 I/I $983^{64}$ (en adelante, Orden de I 3 de abril de I994) y asciende a un máximo de 90I,52 euros.

Respecto a los requisitos exigidos, no van más allá de hallarse al corriente de las obligaciones tributarias y de seguridad social (artículo 2 de la citada orden).

Paralelamente, es de interés señalar que el legislador ha incluido la celebración de contratos temporales dentro de los supuestos que dan lugar a la subvención, siempre y cuando su duración sea igual o superior a I 2 meses en virtud de la disposición adicional II del Real Decreto I45I/I983.

Finalmente, a esta subvención tampoco le son de aplicación las exclusiones previstas en el artículo 6 de la Ley 43/2006, pues como sucedía en la subvención por contrato realizado a personas con discapacidad, su regulación no se encuentra en el programa de fomento del empleo previsto en la citada norma.

En relación a las cuestiones que suscitan más interés, se ha optado por abordar la cuantía y su actualización, y por la posibilidad que permite al trabajador solicitar la subvención de forma supletoria en aquellos casos en los que el empresario no la solicitase.

Respecto la cuantía, ya se advierte que no se trata de un importe fijo, sino que alcanzará como máximo los 901, 52 euros ${ }^{65}$, en virtud del artículo r.2. de la Orden de I3 de abril de I994. Como puede observarse, la cuantía es insuficiente para dar cumplimiento a la triple finalidad prevista por el legislador. En este sentido, la previsión de compatibilidad entre esta subvención y la correspondiente al contrato

64. BOE, núm. I07, de 5 de mayo de I994.

65. La redacción original de la disposición prevé una cantidad máxima de "I 50.000 pesetas por trabajador minusválido contratado [...]", cantidad ésta que al cambio en euros asciende a 901,52 euros. 
realizado a personas con discapacidad ${ }^{66}$, no subsana dicho defecto pues las cuantías siguen siendo escasas.

La segunda cuestión que interesa tratar es la no actualización de la cuantía de la subvención desde su creación en I994, ni tan siquiera conforme a las fluctuaciones del Índice de Precios al Consumo (IPC) ${ }^{67}$.

Se desconocen las razones de esta omisión, pero los efectos derivados son devastadores. Ya no tan solo por la pérdida de valor, que alcanza en la actualidad los 67,9 puntos porcentuales, sino por la incongruencia del legislador entre objetivos propuestos y actuaciones realizadas.

En este sentido, las contradicciones se observan respecto a las líneas operativas cinco y seis del objetivo número seis previsto en la Estrategia Global, que persigue la mejora de la calidad del empleo. Las previsiones del citado texto van encaminadas a incrementar las ayudas para la adaptación de puestos de trabajo, e incluso ampliarlas para casos de discapacidad sobrevenida, entre otros, pretensiones éstas que distan mucho de las actuaciones legislativas llevadas a cabo durante los últimos años.

Paralelamente, los efectos negativos de esta omisión se extienden a otras obligaciones del ordenamiento jurídico, como por ejemplo la de realizar ajustes razonables (artículo 40.2 LGDPD), toda vez que influye directamente en la determinación de la carga excesiva que da lugar a la exención de la obligación.

66. Vid. artículo I.2 de la Orden de I 3 de abril de I 994 por la que se regula la concesión de las ayudas y subvenciones sobre fomento del empleo de los trabajadores minusválidos que establece el Capítulo II del Real Decreto I45I/I983, de I I de mayo, el cual preceptúa que "dichas ayudas son compatibles con la subvención, por importe máximo de I 50.000 pesetas, por trabajador minusválido contratado, destinado a la adaptación de los puestos de trabajo o dotación de medios de protección personal necesarios para evitar accidentes laborales al trabajador minusválido contratado".

67. A septiembre de 2013 , el importe actualizado de la cuantía ascendería a I.5 I3,65 euros, esto es, un incremento del 67,9\% sobre la cantidad inicial, según la actualización de rentas con el IPC general (sistema IPC base 20I I) para períodos anuales completos del INE, <http://www.ine.es/calcula/>.
Es por ello que el mantenimiento de una actitud pasiva sobre esta cuestión es inadmisible. El legislador debe ampliar la cuantía de la subvención urgentemente, o como mínimo, proceder a su actualización conforme al Índice de Precios al Consumo, en tanto que dicha omisión desnaturaliza la finalidad incentivadora de la subvención y afecta negativamente a factores que condicionan el cumplimiento de otras obligaciones previstas.

La tercera cuestión objeto de estudio es la posibilidad, por parte del trabajador, de solicitar la ya citada subvención de forma subsidiaria, cuando el empresario no la haya solicitado. Partiendo de que el requisito esencial fijado por el artículo 2 de la Orden de I 3 de abril de 1994 es la acreditación previa por parte del beneficiario de hallarse al corriente de las obligaciones tributarias y frente a la Seguridad Social, así como también la justificación mediante factura que acredite la adaptación o dotación realizada y el informe favorable de la Inspección de Trabajo y de la Seguridad Social, al amparo del artículo I.2 in fine de la citada Orden, la pregunta que irremediablemente surge es si debe el trabajador, en su caso, justificar tales obligaciones de la empresa, que es la única beneficiaria ${ }^{68}$ de la subvención.

La respuesta a la cuestión planteada transita en torno a la distinción entre el sujeto solicitante y el sujeto beneficiario de la subvención.

La noción legal de sujeto beneficiario y solicitante de la ya citada subvención identifica como tal al empresario, que es quien debe justificar el cumplimiento de los requisitos.

Ahora bien, la posibilidad prevista en el artículo I 2 in fine del Real Decreto I45I/I98 3 única y exclusivamente faculta al trabajador para

68. En este sentido, conviene señalar que el hecho de que la citada orden prevea que el trabajador solicite la subvención como posibilidad subsidiaria, ello no significa que el sujeto beneficiario de la subvención pase a ser el trabajador, pues las finalidades previstas para la subvención forman parte de obligaciones que corresponden al empresario en virtud del artículo 37.bis.2 LISMI y del artículo I4.I de la Ley 3 I/I995 de prevención de riesgos laborales. 
tramitar la solicitud de la subvención, y en ningún caso transmite las obligaciones que le corresponden al empresario.

\section{Conclusiones}

- Primera. En lo que concierne a las bonificaciones en materia de Seguridad Social, se trata de una medida generosa si las comparamos con las bonificaciones previstas para otros colectivos, lo que se ve realzado por la adaptación de sus cuantías a la diversa gravedad de la discapacidad de los trabajadores. Sin embargo, entendemos que una mejor adaptación a los criterios de la Estrategia Global exigiría la exención total de bonificaciones para supuestos de contratación de personas con especiales dificultades.

- Segunda. Asimismo, desde una perspectiva de calidad en el empleo, sería conveniente retomar una lógica de porcentajes de bonificación, más que la fijación de cuantías máximas de bonificación, ya que ello desincentiva las mejoras y/o actualizaciones salariales y por ende acaba obstaculizando la calidad en el empleo. Además, con algunas cautelas, entendemos que las bonificaciones deberían extenderse a los contratos temporales estructurales, eventual y de obra o servicio determinado, ya que ello acaba redundando en una mayor incentivación que acabará generando una mayor tasa de empleo, lo que encaja en la lógica de la los principios de la LGDPD.

- Tercera. Respecto a las exclusiones en materia de bonificaciones a la Seguridad Social, el planteamiento es en general aceptable, ya que su regulación favorece el principio de desarrollo profesional de las personas con discapacidad, su calidad en el empleo, la transición del empleo protegido al empleo ordinario así como el derecho de retorno a los Centros Especiales de Empleo. Asimismo, el régimen adaptado de exclusiones es muy interesante porque amplía las posibilidades de empleo del colectivo, no impidiendo contrataciones en entornos empresariales familiares, ni el desempeño de actividades bonificadas en el marco de relaciones laborales especiales.

- Cuarta. La previsión de dos subvenciones es insuficiente para promover el incremento del empleo de las personas con discapacidad. El cumplimiento de tal objetivo requiere la creación de nuevas subvenciones que complementen las actuales y, muy especialmente, es imprescindible que las comunidades autónomas cuenten con recursos suficientes que les permitan efectuar convocatorias de las mismas, lo que no siempre sucede.

- Quinta. La subvención por contrato realizado necesita una puesta al día para recobrar su eficacia incentivadora inicial. La flexibilización del requisito de sustitución del trabajador contratado, y la mejora de la cuantía, que no ha sido actualizada desde I999, son algunos de los puntos que deben remediarse cuanto antes.

A ello debe sumársele la necesidad de flexibilizar el porcentaje de compatibilidad entre la subvención estatal por contrato realizado y las subvenciones previstas por las comunidades autónomas, en función del sexo, el tipo y grado de discapacidad o la edad. Paralelamente, el legislador ha de tomar nota del régimen autonómico en materia de subvenciones por contrato realizado, pues prevén mayores cuantías y valoran para la determinación de la cantidad a conceder factores como el sexo, la edad o el tipo de discapacidad.

- Sexta. La subvención de fomento del empleo y adaptación del puesto de trabajo también necesita una reformulación que incremente su cuantía, escasa para la triple finalidad prevista legalmente, y defina la previsión subsidiaria de solicitud por parte del trabajador.

- Séptima. Con carácter general, se echa de menos la plasmación de la propuesta expresada en la Estrategia Global, en el 
sentido de sobreincentivar la contratación cuando la empresa no esté obligada al cumplimiento de la reserva de empleo, o bien cuando contrate por encima de su obligación de reserva. A este respecto, la puesta en práctica de este criterio, que podría aplicarse a bonificaciones y a las subvenciones, peligra actualmente dada la súbita e injustificada desaparición del principio de preferencia por el empleo en el medio ordinario de trabajo operada mediante la LGDPD.

\section{Referencias bibliográficas}

Alemán, F. y Grau, C. (20II): "La inserción laboral de las personas con diversidad funcional. Bases para un modelo social de discapacidad", Documentación Laboral, 92: I I-56.

Cordero, V. (20I I): "El fomento del empleo de las personas con discapacidad por las Comunidades Autónomas" en VV.AA.: Los nuevos marcos de relaciones laborales en el renovado estado de las autonomías: XXI Congreso Nacional de Derecho del Trabajo $y$ de la Seguridad Social, Valencia: Tirant Lo Blanch: 253-270.

Esteban, R. (20I3): “La Estrategia global de empleo de las personas con discapacidad. Un balance crítico tras su finalización", Revista de Derecho Social, 63: 43-70.

Esteban, R. y Pérez, J. (2009): "Los incentivos laborales a la actividad en Centros Especiales de Empleo”, en Esteban, R. y Pérez, F. (dirs): La aplicación del Derecho del Trabajo en los Centros Especiales de Empleo, Valencia: Tirant lo Blanch: $30 \mathrm{I}-348$.

Instituto Nacional de Estadística (2010): El salario de las personas con discapacidad. Año 2010 , Notas de Prensa INE, 5 de junio de 2013.

Lahera, J. (2005): “Acceso al Mercado laboral y contratación de los discapacitados", en Valdés, F. (dir.) y Lahera, J. (coords.): Las relaciones laborales de las personas con discapacidad, Madrid: Editorial Biblioteca Nueva: 89-I40.

López, F. (2004): "Las fuentes jurídicas del empleo" en Cardona, M. B., et al.: Derecho del
Empleo, Valencia: Tirant Lo Blanch, $2^{a}$ edición,: 69-II 5 .

Pérez J. (2008): "El fomento del empleo de las personas con discapacidad: técnicas de incentivación y entornos normativos protectores", Revista del Instituto de Estudios Económicos, núm. 2-3: 293-322.

Rodríguez, G. et al. (2009): Evaluación de las politicas de empleo para personas con discapacidad y formulación y coste económico de nuevas propuestas de integración laboral, Madrid: Editorial Cinca.

Rubio, $M^{a}$ D. (2006): "El contrato temporal de fomento de empleo para personas con discapacidad: dificultando la integración laboral", Actualidad Jurídica Aranzadi, 7I 8: I-9 (en línea). <www.westlaw.es>, acceso 7 de febrero de 20I4.

Ysàs, H. (20I3): "Diálogo social y diálogo civil en el ámbito del empleo de las personas con discapacidad: la Estrategia Global de Acción”, Revista Española de Derecho del Trabajo, I 59: I 83-2I 2 .

\section{Referencias legislativas}

Cantabria. Orden $\mathrm{HAC} / 23 / 20{ }_{3}$, de I 3 de mayo por la que se establecen las bases reguladoras y se aprueba la convocatoria de subvenciones destinadas a incentivar la contratación indefinida de personas en situación de 
desempleo. Boletín Oficial de Cantabria, núm. 98 de 24 de mayo de 2013 , p. I7I75-I7I92.

Castilla-La Mancha. Decreto 39/2013, de I I de julio, por el que se regula los incentivos destinados a fomentar la contratación de las personas con discapacidad en el mercado ordinario de trabajo de Castilla-La Mancha. Boletín Oficial de Castilla La Mancha, núm. I37 de I7 de julio de 20I3, p. I9257-I9266.

Comunidad Valenciana. Orden I3/20I 3 de 2 I de mayo, de la Consejería de Economía, Industria, Turismo y Empleo, por la que se convoca y regula la concesión de subvenciones públicas destinadas al fomento del empleo para personas con discapacidad en el ejercicio 2013. Diario Oficial de la Comunidad Valenciana, núm. 7036 de 3 I de mayo de 2013 , p. I60II- I603I.

España. Real Decreto Legislativo I/20I3, de 29 de noviembre, por el que se aprueba el Texto Refundido de la Ley General de derechos de las personas con discapacidad y de su inclusión social. Boletín Oficial del Estado, núm. 289, de 3 de diciembre de 2013, p. 95635 a 95673 .

España. Real Decreto-Ley 20/20I2, de I3 de julio, de medidas para garantizar la estabilidad presupuestaria y de fomento de la competitividad. Boletín Oficial del Estado, núm. I68, de I4 de julio de 20I2, p. 50428 a 50518 .

España. Ley 3/20I 2, de 6 de julio, de medidas urgentes para la reforma del mercado laboral. Boletín Oficial del Estado, núm. I 62, de 7 de julio de 20I 2, p. 49II3-49I9I.

España. Real Decreto-Ley 3/20I2, de Io de febrero, de medidas urgentes para la reforma del mercado laboral. Boletín Oficial del Estado, núm. 36 de $\mathrm{I} 2$ de febrero de $20 \mathrm{I} 2$, p. I 2483 -I 2546 .

España. Real Decreto-ley 3/20I I, de I 8 de febrero, de medidas urgentes para la mejora de la empleabilidad y la reforma de las políticas activas de empleo. Boletín Oficial del Estado, núm. 43, de I9 de febrero de $201 \mathrm{I}$, p. 19240 a 19260.
España. Ministerio de Trabajo e Inmigración, Ministerio de Sanidad y Política Social (2009): "Estrategia Global de Acción para el Empleo de las Personas con Discapacidad 2008-20I 2", Madrid: Ministerio de Trabajo e Inmigración, Ministerio de Sanidad y Política Social (en línea). <http://www.empleo.gob. es/es/sec_trabajo/estrategia_global_personas_ discapacidad_2008_2OI2.pdf $>$, acceso I4 de mayo de 2014 .

España. Instrumento de ratificación de la Convención sobre los Derechos de las Personas con Discapacidad, hecho en Nueva York el I3 de diciembre de 2006. Boletín Oficial del Estado, núm. 96, de 2I de abril de 2008, p. 20648 a 20659.

España. Real Decreto 870/2007, de 2 de julio, por el que se regula el programa de empleo con apoyo como medida de fomento de empleo de personas con discapacidad en el mercado ordinario de trabajo, Boletín Oficial del Estado, núm. I68, de I4 de julio de 2007 , p. 30618-30622.

España. Ley 43/2006, de 29 de diciembre, para la mejora del crecimiento y del empleo. Boletín Oficial del Estado, núm. 3 I 2, de 30 de diciembre de 2006, p. 46586 a 46600.

España. Real Decreto-Ley 5/2006, de 9 de junio, para la mejora del crecimiento y del empleo. Boletín Oficial del Estado, núm. I4I, de I4 de junio de 2006, p. 22670 a 22682.

España. Ley 56/2003, de I 6 de diciembre, de Empleo, Boletín Oficial del Estado, núm. $30 \mathrm{I}$ de I7 de diciembre de 2003, p. 44763-4477I.

España. Ley 5I/2003 de 2 de diciembre, de igualdad de oportunidades, no discriminación, y accesibilidad universal de las personas con discapacidad. Boletín Oficial del Estado, núm. 289 , de 3 de diciembre de 2003 , p. 43I87-43I95.

España. Ley 38/2003, de 17 de noviembre, General de Subvenciones. Boletín Oficial del Estado, núm. 276, de I 8 de noviembre de 2003 , p. 40505 a 40532 .

España. Real Decreto Legislativo 5/2000, de 4 de agosto, por el que se aprueba el texto refundido 
de la Ley sobre Infracciones y Sanciones en el Orden Social. Boletín Oficial del Estado, núm. I 89 , de 8 de agosto de 2000 , p. $28285-28300$.

España. Real Decreto I97I/I999, de 23 de diciembre, de procedimiento para el reconocimiento, declaración y calificación del grado de minusvalía. Boletín Oficial del Estado, núm. 22, de 26 de enero de 2000, p. 33I7-34IO.

España. Orden de I 6 de octubre de I 998 por la que se establecen las bases reguladoras para la concesión de las ayudas y subvenciones públicas destinadas al fomento de la integración laboral de los minusválidos en centros especiales de empleo y trabajo autónomo. Boletín Oficial del Estado, núm. 279, de 2 I de noviembre de I998, p. 384II a 384 I4.

España. Orden de I3 de abril de I994 por la que se regula la concesión de las ayudas y subvenciones sobre fomento del empleo de los trabajadores minusválidos que establece el capítulo II del Real Decreto I45I/I983, de I I de mayo. Boletín Oficial del Estado, núm. I07 de 5 de mayo de I994, p. I3870-I387I.

España. Real Decreto I45I/I983, de I I de mayo, por el que en cumplimiento de lo previsto en la Ley I3/I982, de 7 de abril, se regula el empleo selectivo o las medidas de fomento del empleo de los trabajadores minusválidos. Boletín Oficial del Estado, núm. I33, de 4 de junio de I983, p.I 5548 a I 5549 .

España. Ley I3/I982, de 7 de abril, de integración social de los minusválidos. Boletín Oficial del Estado, núm. I03, de 30 de abril de I982, p. IIIO6 a IIII2.

España. Constitución Española. Boletín Oficial del Estado, núm. 3 I I, de 29 de diciembre de 1978 , p. 293 I 3 a 29424.
Extremadura. Orden de 6 de agosto de 2013 por la que se convoca la concesión de incentivos destinados a favorecer la contratación de personas con discapacidad en el mercado ordinario de trabajo en la Comunidad Autónoma de Extremadura para el ejercicio 2013. Diario Oficial de Extremadura, núm. I 57 de I4 de agosto de 20I3, p. I9787-I9804.

Extremadura. Decreto I49/20I2, de 27 de julio, por el que se regulan los incentivos destinados a favorecer la contratación de personas con discapacidad en el mercado ordinario de trabajo y se aprueba la primera convocatoria de dichas subvenciones. Diario Oficial de Extremadura, núm. I 49 de 2 de agosto de 20I2, p. I7076-I7II2.

Islas Baleares. Resolución del Consejero de Economía y Competitividad de 17 de mayo de 2013 por la que se aprueba la convocatoria para conceder ayudas sobre el fomento del empleo de las personas con discapacidad que establece el Capítulo II del Real Decreto I45I/I983, de I I de mayo. Boletín Oficial de Islas Baleares, núm. 77 de I de junio de 2013 , p. 2480 I-248 I 5 .

Navarra. Resolución 795/2013, de I6 de mayo, de la Directora Gerente del Servicio Navarro de Empleo, por la que se aprueba la convocatoria de subvenciones para favorecer la inserción laboral de personas con discapacidad en el mercado ordinario de trabajo de 30 de mayo de 20I3, p. $5857-5860$.

Región de Murcia. Orden de ro de julio de 20I3, del Presidente del Servicio Regional de Empleo y Formación, de bases reguladoras de los programas de subvenciones para el fomento de la integración laboral de personas con discapacidad. Boletín Oficial de la Región de Murcia, núm. I63 de I 6 de julio de 2013, p. 287I 8-28770. 